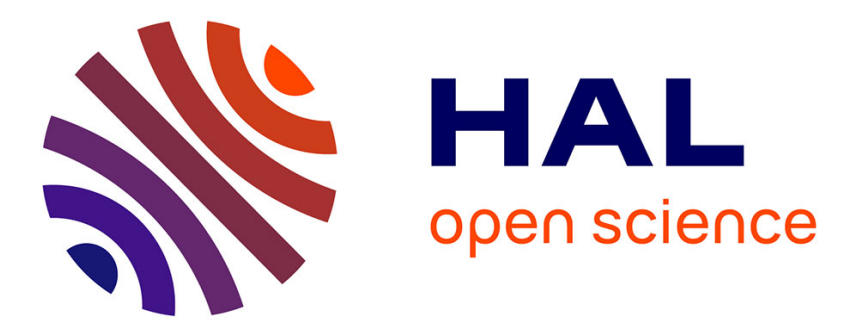

\title{
Experimental study of smectite interaction with metal iron at low temperature: 1. Smectite destabilization.
}

Sébastien Lantenois, Bruno Lanson, Fabrice Muller, Andreas Bauer, Michel Jullien, Alain Plançon

\section{- To cite this version:}

Sébastien Lantenois, Bruno Lanson, Fabrice Muller, Andreas Bauer, Michel Jullien, et al.. Experimental study of smectite interaction with metal iron at low temperature: 1. Smectite destabilization.. Clays and Clay Minerals, 2005, 53, pp.597-612. 10.1346/CCMN.2005.0530606 . hal-00022201

\section{HAL Id: hal-00022201 \\ https://hal-insu.archives-ouvertes.fr/hal-00022201}

Submitted on 4 Apr 2006

HAL is a multi-disciplinary open access archive for the deposit and dissemination of scientific research documents, whether they are published or not. The documents may come from teaching and research institutions in France or abroad, or from public or private research centers.
L'archive ouverte pluridisciplinaire HAL, est destinée au dépôt et à la diffusion de documents scientifiques de niveau recherche, publiés ou non, émanant des établissements d'enseignement et de recherche français ou étrangers, des laboratoires publics ou privés. 


\section{Experimental study of smectite interaction with metal iron}

\section{at low temperature: 1 . Smectite destabilization.}

\section{Sébastien Lantenois $^{(1)} *$, Bruno Lanson ${ }^{(2)}$, Fabrice Muller ${ }^{(1)}$, Andreas Bauer ${ }^{(3)}$, Michel} Jullien $^{(4)}$, Alain Plançon ${ }^{(1)}$

(1) Institut des Sciences de la Terre d'Orléans (ISTO), CNRS - Université d'Orléans, 1A rue de la Férollerie, 45071 Orléans Cedex 2, France.

(2) Environmental Geochemistry Group, LGIT, Maison des GéoSciences, Université J. Fourier-CNRS, BP 53, 38041 Grenoble Cedex 9, France.

(3) Institut für Nukleare Entsorgung, Forschungzentrum Karlsruhe, P.O. Box 3640, 76021 Karlsruhe Germany.

(4) Commissariat à l'Energie Atomique (CEA), Centre d'Etude de Cadarache DEN/DTN/SMTM/Laboratoire de Modélisation des Transferts dans l'Environnement, Bat 307, 13108 Saint Paul Lez Durance Cedex, France.

\footnotetext{
* Author to whom correspondence should be addressed.

e-mail: sebastien.lantenois@univ-orleans.fr
}

KEYWORDS: nuclear waste disposal, engineered barrier, clay barrier, iron-clay interactions, iron corrosion, clay stability, X-ray diffraction, smectite. 
Interaction between metal iron and a variety of natural and synthetic smectites samples with contrasting crystal chemistry was studied by scanning electron microscopy and X-ray

diffraction (XRD) from experiments conducted at $80^{\circ} \mathrm{C}$. These experiments demonstrate an important reactivity contrast as a function of smectite crystal chemistry. An XRD quantification method involving the use of an internal standard allowed quantification of the relative proportion of smectite destabilized as a function of initial $\mathrm{pH}$ conditions as well as of smectite structural parameters. In mildly acidic to neutral $\mathrm{pH}$ conditions, a significant proportion of metal iron is corroded to form magnetite without smectite destabilization. Under basic $\mathrm{pH}$ conditions, smectite and metal iron are partly destabilized to form magnetite and newly-formed 1:1 phyllosilicate phases (odinite and crondstedtite). Systematic destabilization of both metal iron and smectite is observed for dioctahedral smectites while trioctahedral smectites are essentially unaffected under similar experimental conditions. Smectite reactivity is enhanced with increasing $\mathrm{Fe}^{3+}$ content and with the presence of $\mathrm{Na}^{+}$cations in smectite interlayers. A conceptual model for smectite destabilization is proposed. This model involves first the release of protons from smectite structure, $\mathrm{MeFe}^{3+} \mathrm{OH}$ groups being deprotonated preferentially and metal iron acting as proton acceptor. Corrosion of metal iron results from its interaction with these protons. $\mathrm{Fe}^{2+}$ cations resulting from this corrosion process sorb on the edges of smectite particles and lead to induce the reduction of structural $\mathrm{Fe}^{3+}$ and migrate into smectite interlayers to compensate for the increased layer charge deficit. Interlayer $\mathrm{Fe}^{2+}$ cations subsequently migrate to the octahedral sheet of smectite because of the extremely large layer charge deficit. At low temperature, this migration is favored by the reaction time and by the absence of protons within the di-trigonal cavity. Smectite destabilization results 
46 from the inability of the tetrahedral sheets to accommodate the larger dimensions of the newly

47 formed trioctahedral domains resulting from the migration of $\mathrm{Fe}^{2+}$ cations. 
In some of the "multi-barriers" concepts envisaged for the storage of high- and

intermediate-level and/or long-lived nuclear waste, metallic containers filled with vitrified nuclear waste are placed in a confinement barrier itself surrounded by a geological barrier. The reactive components of the engineered and geological barriers are clays (mainly smectites) while metallic containers could be made up of iron. To predict the long-term properties of these clay barriers, it is thus essential to study the interactions between clay minerals, and more especially smectite, and metal iron as the corrosion of the metallic canister could induce in turn the destabilization of the clay minerals.

Studies of these iron-clay interactions have shown indeed the partial but systematic destabilization of the initial clay material and the subsequent crystallization of reaction products (Habert, 2000; Perronnet, 2001, 2004; Kohler, 2001; Lantenois, 2003; Guillaume et al., 2003). The nature of these reaction products depends on experimental conditions such as temperature and, to a minor extent, the nature of the initial clay material. When smectite is used, iron-rich chlorite-like species are synthesized at high temperature $\left(300^{\circ} \mathrm{C}\right.$ - Guillaume et al., 2003) whereas iron-rich serpentine-like species are obtained for temperatures more realistic in the context of nuclear waste disposal $\left(80^{\circ} \mathrm{C}\right.$ - Habert, 2000; Perronnet, 2001, 2004; Lantenois, 2003). Newly formed 1:1 phyllosilicates with low iron content were also identified by Kohler (2001) after reaction between iron metal and kaolinite/smectite mixtures at $80^{\circ} \mathrm{C}$.

As reaction pathways appear to vary significantly as a function of temperature (Guillaume et al., 2003; Lantenois, 2003), it is especially important to work at temperatures similar to those expected during storage lifetimes, thus generally excluding medium-to-high temperature experiments $\left(>200^{\circ} \mathrm{C}\right)$. Experimental conditions have been chosen to mimic those of the repository, and experiments were thus performed in an anoxic and reducing 
environment. The clay materials used for this study were essentially natural smectites which have swelling and self-healing abilities and cation retention properties suitable for engineered barriers. To promote the reactivity of clays so that significant reaction progress could be obtained on a laboratory-compatible timescale, the water/solid ratio was significantly increased.

A method has been developed to quantify the amount of smectite destabilized as a result of its interaction with metal iron. The aim of the present study was to determine the role of the nature of clay minerals on the contrasting reactivity observed during their hydrothermal reaction with iron metal by using a variety of starting materials. Specifically, the structural characteristics responsible for these differences were sought, together with the mechanism of clay destabilization. The companion paper (Lantenois et al., 2005) will describe the crystalchemistry of newly-formed phases.

\section{MATERIALS AND METHODS}

\section{Materials}

A variety of natural and synthetic smectite samples with contrasting crystal chemistry were used in the present study. These samples were selected to include both di- and trioctahedral varieties, smectite with octahedral or tetrahedral substitutions, and to cover a wide range of chemical composition, focusing on the iron content. Chemical compositions of selected samples are reported in Table 1. Untreated bulk samples were ground in an agate mortar to increase their reactivity, but samples were neither size-fractionated nor purified. Synthetic clays were crystallized from gels under hydrothermal conditions. Gels were prepared following a method adapted from Hamilton and Henderson (1968) using tetraethyl 
orthosilicate (TEOS), $\mathrm{Mg}\left(\mathrm{NO}_{3}\right)_{2} \cdot 6 \mathrm{H}_{2} \mathrm{O}, \mathrm{Al}\left(\mathrm{NO}_{3}\right)_{3} .9 \mathrm{H}_{2} \mathrm{O}, \mathrm{Fe}\left(\mathrm{NO}_{3}\right)_{3} .9 \mathrm{H}_{2} \mathrm{O}, \mathrm{HNO}_{3}, \mathrm{Na}_{2} \mathrm{CO}_{3}$, $\mathrm{NH}_{4} \mathrm{OH}$ and ethanol. All reagents had a 99\% minimum grade. After dissolution of Al- and Mg-nitrates and of $\mathrm{Na}_{2} \mathrm{CO}_{3}$ in nitric acid, TEOS and ethanol were added. A precipitate was obtained by neutralizing the resulting solution at $\mathrm{pH} \sim 6$ with addition of $\mathrm{NH}_{4} \mathrm{OH}$. This precipitate was dried at $80^{\circ} \mathrm{C}$ for 24 hours, ground in an agate mortar and heated to $400^{\circ} \mathrm{C}$ to remove nitrates and carbonates and to obtain a gel composed essentially of $\mathrm{Al}, \mathrm{Mg}, \mathrm{Si}$ and $\mathrm{Na}$ oxides. SapFe08 saponite was synthesized from such gels in a cold-sealed pressure vessel. Gel and deionized water were introduced in a 2:1 weight ratio in a silver tube itself placed in the vessel heated at $400^{\circ} \mathrm{C}$ for one month at an estimated pressure of $100 \mathrm{MPa}$ (Suquet et al., 1977). The SbS-1 beidellite was synthesized in an internally heated pressure vessel. $600 \mathrm{mg}$ of gel were mixed to $1.3 \mathrm{~g}$ of a $\mathrm{NaOH}$ solution $(0.2 \mathrm{~N})$ in a gold tube. The tube was then sealed and heated to $350^{\circ} \mathrm{C}$ under $22 \mathrm{MPa}$ for 10 days (Kloprogge et al., 1999). After cooling of the vessels, the solid products were extracted from the reaction tubes, dried at $80^{\circ} \mathrm{C}$ overnight, and ground before structural and chemical characterization using X-ray diffraction (XRD) and energy dispersive X-ray fluorescence spectroscopy (EDS) on a transmission electron microscope (TEM).

To better assess the role of the interlayer composition on the reaction rate K-, Na-, and Ca-saturated specimens were prepared for samples SWy-2, Garfield, and SAz-1. The cation exchange procedure was performed at room temperature by immersing the ground clay sample in $1 \mathrm{M} \mathrm{KCl}, \mathrm{NaCl}$ or $\mathrm{CaCl}_{2}$ aqueous solutions. After 12 hours of contact, the solid was extracted by centrifugation. The saturation procedure was repeated four times. The excess chloride was then removed by washing the sample five times with distilled water (K- and Casaturated samples). Na-saturated samples were washed once in ethanol, and then dialysed in deionized water for one week. 
Experimental

For the iron-clay interactions, $0.6 \mathrm{~g}$ of the clay powder were mixed with $0.6 \mathrm{~g}$ of metal iron powder (10 $\mu \mathrm{m}$ maximum size, Merck $^{\circledR}$ product for analysis) to maximize the contact surface between iron and clay particles. The large amount of metal iron was intended also to promote reducing conditions during the experiments. $30 \mathrm{~mL}$ of water were added to this

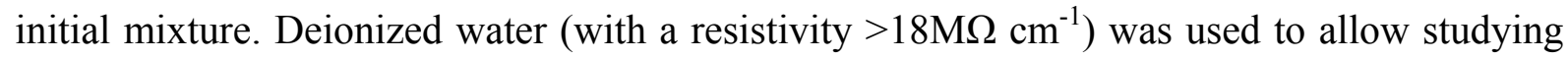
the final solution composition. Samples were prepared in a MBraun ${ }^{\circledR}$ glove box equipped with copper catalysts to eliminate $\mathrm{O}_{2}$, and a $\mathrm{MBraun}{ }^{\circledR} \mathrm{O}_{2}$ control system. Partial pressure of $\mathrm{O}_{2}$ was lower than $1 \mathrm{ppm}$ during sample preparation. Deionized water was degassed with Argon for one hour prior to its introduction in the glove box and all products were allowed to stay in the glove box for 24 hours to equilibrate with the glove box atmosphere. Starting products were then placed in $40 \mathrm{~mL}$ Nalgene ${ }^{\circledR}$ reactors. Because these reactors are oxygen porous, a "double enclosure system" was used where the Nalgene ${ }^{\circledR}$ reactors were inserted into larger Teflon ${ }^{\circledR}$ reactors which contain metal iron powder, $\mathrm{FeSO}_{4}$ and water. Any oxygen entering the Teflon reactors was thus eliminated according to reactions (1) and (2) with ferrous and metal iron, respectively (Aogaki, 1999).

$$
\begin{gathered}
2 \mathrm{Fe}^{2+}+1 / 2 \mathrm{O}_{2}+3 \mathrm{H}_{2} \mathrm{O} \rightarrow 4 \mathrm{H}^{+}+2 \mathrm{FeOOH} \\
2 \mathrm{Fe}^{\circ}+3 / 2 \mathrm{O}_{2}+3 \mathrm{H}_{2} \mathrm{O} \rightarrow 2 \mathrm{Fe}(\mathrm{OH})_{3}
\end{gathered}
$$

The two reactors were tightly closed within the glove box and subsequently heated at $80^{\circ} \mathrm{C}$ for 45 days outside of the glove box. Additional experiments were also performed for 5 , 15, 30, 60, 90 and 120 days on selected samples (Garfield, SbId, SWy-2 and SapCa-2). At the end of the reactions, reactors were cooled down to room temperature and opened in air, the solution $\mathrm{pH}$ being measured immediately. The solution was subsequently filtered $(0.45 \mu \mathrm{m})$ 
and acidified for chemical analysis, whereas the solid fraction was dried at $80^{\circ} \mathrm{C}$ overnight and ground.

Filtered solutions were analyzed for major and trace elements ( $\mathrm{Si}, \mathrm{Al}, \mathrm{Fe}, \mathrm{Mg}, \mathrm{Ti}, \mathrm{Na}$, $\mathrm{Ca}$ and $\mathrm{K}$ ) with an ICP-AES Jobin-Yvon ULTIMA spectrometer. Scanning electron microscopy (SEM) was performed using a JEOL 6400 microscope. Samples were covered with a $\mathrm{Au}$ film before observation to avoid charge build up. TEM was performed using a JEOL 2000 FX microscope operated at $200 \mathrm{kV}$. Samples were prepared as a suspension in deionized water, a drop of this suspension being dried on copper grids covered with a carbon film.

Powder XRD patterns were recorded in transmission geometry using CoK $\alpha$ radiation $(35 \mathrm{~mA}, 35 \mathrm{kV})$ to avoid iron fluorescence. The use of an INEL CPS 120 curved position sensitive detector allowed recording simultaneously the diffracted intensity over a $4-50^{\circ} 2 \theta$ range with a step size of $0.03^{\circ}$. The non-linearity of the detector was corrected (Roux and Wolfinger, 1996). A $0.5 \mathrm{~mm}$ diameter Lindemann glass tube was used to hold the sample powder.

Infrared (IR) spectra were recorded over the $650-4000 \mathrm{~cm}^{-1}$ range with a $2 \mathrm{~cm}^{-1}$ resolution using a Nicolet Magna-IR Fourier transform spectrometer equipped with a Globar SiC source and a DTGS detector. The spectrometer was purged with dry air prior to data collection to remove most of atmospheric $\mathrm{H}_{2} \mathrm{O}$. The sample was finely ground in an agate mortar, and $0.5 \mathrm{mg}$ of the resulting powder was mixed to $150 \mathrm{mg}$ of $\mathrm{KBr}$ previously dried at $120^{\circ} \mathrm{C}$ for 24 hours. The mixture was homogenized and pressed in an evacuable die to prepare a $12 \mathrm{~mm}$ diameter pellet. Decomposition of the IR spectra in the $\mathrm{OH}$ bending region $\left(700-900 \mathrm{~cm}^{-1}\right)$ was performed with Peak-Fit (v4.05).

The cation exchange capacity (CEC) was measured using the copper complex method (Gaboriau, 1991). $600 \mathrm{mg}$ of sample were suspended for 12 hours in $25 \mathrm{~mL}$ of a $0.02 \mathrm{~N}$ 
ethylene di-amine copper complex $\left(\mathrm{Cu}(\mathrm{EDA})_{2} \mathrm{Cl}_{2}\right)$ solution. After centrifugation, the $\mathrm{Cu}$ concentration in solution was measured using a 905-GBC atomic absorption spectrophotometer from GBC Scientific Equipment.

\section{Quantification of the relative proportion of smectite destabilized after reaction}

To estimate reaction progress, the amount of residual smectite was quantified by XRD using the internal standard technique adapted to clays by Hillier (2000). As recommended by this author, each sample was mixed with $10 \%$ of a corundum internal standard (particle size $<50 \mu \mathrm{m})$, dry ground in an agate mortar for 10 minutes and then introduced in the Lindeman glass tube. The use of a glass tube in transmission geometry allows optimizing sample disorientation. Segregation due to particle size and/or particle density was minimized by careful grinding and mixing. Absorption corrections have not been considered because absorption, which is closely related to sample chemical composition, is similar before and after reaction.

The (001) reflection of smectite was not selected for quantification, because its intensity strongly depends on smectite hydration state and thus on the chemical composition of smectite interlayers, which can be modified during the reaction. The amount of residual smectites was rather quantified by measuring the integrated intensity of the $(02,11)$ band (between $22.0^{\circ}$ and $27.0^{\circ} 2 \theta \mathrm{CoK} \alpha$ - Figure 1) before and after reaction, these intensities being normalized to the (012) reflection of corundum $\left(29.8^{\circ} 2 \theta \mathrm{CoK} \alpha\right.$ - Figure 1). Background was assumed to be linear between 22.0 and $27.0^{\circ} 2 \theta$ and subtracted. If quartz impurities were present, the (100) reflection of quartz $\left(\sim 24.3^{\circ} 2 \theta \mathrm{CoK} \alpha\right)$ was fitted, and its integrated intensity subtracted from the total integrated intensity. To assess the validity of $\mathrm{XRD}$ results, the relative proportion of reacted smectite was also quantified from CEC 
measurements performed before and after reaction, the observed CEC decrease being directly linked to the amount of destabilized smectite. This assumption was made possible by the nonswelling character of the reaction products (Lantenois, 2003; Lantenois et al., 2005).

The amount of residual smectite was also quantified using IR spectroscopy. Over the $\mathrm{OH}$ bending frequency range, three bands at $912-920 \mathrm{~cm}^{-1}, 874-886 \mathrm{~cm}^{-1}$, and $840-850 \mathrm{~cm}^{-1}$ correspond to the $\mathrm{Al}-\mathrm{Al}-\mathrm{OH}, \mathrm{Al}-\mathrm{Fe}-\mathrm{OH}$ and $\mathrm{Al}-\mathrm{Mg}-\mathrm{OH}$ vibrations of smectites, respectively (Farmer, 1974; Goodman et al., 1976; Russell and Fraser, 1994; Vantelon et al., 2001). The position reported in the literature for the $\mathrm{Fe}-\mathrm{Fe}-\mathrm{OH}$ band scatters from $820-795 \mathrm{~cm}^{-1}$ (Goodman et al., 1976; Cuadros and Altaner, 1998) and overlaps with the Si-O vibrations of quartz at 780 and $800 \mathrm{~cm}^{-1}$ (Madejova and Komadel, 2001). To avoid using this problematic band, reaction progress was quantified using IR spectroscopy for Fe-poor smectites only. The quantification method itself requires subtracting a baseline which corresponds to $\mathrm{Si}-\mathrm{O}$ vibrations in phyllosilicates (Figure 2a - Vantelon et al., 2001). A cubic spline baseline, similar for all samples, was adjusted on both sides of the region of interest $\left(817-822 \mathrm{~cm}^{-1}\right.$ and $940-945 \mathrm{~cm}^{-1}$, respectively). The $822-945 \mathrm{~cm}^{-1}$ range of the baseline-corrected spectra was then fitted with three Gaussian-shaped curves (Figures $2 \mathrm{~b}$ ) corresponding to Al-Al-OH, AlFe-OH and Al-Mg-OH vibration modes. Relative proportion of unaltered smectite was estimated from the ratio between the total surface areas determined for these three contributions before and after reaction. 
Qualitative evaluation of the reaction progress

Long-term experiments show that the reaction progress reaches a plateau after about 30 days (see below). Except when specifically notified, reactions described in the following section were thus performed for 45 days, without constraining the solution $\mathrm{pH}$. The observed reaction depends on the nature of the initial smectite sample. In particular di- and trioctahedral smectites exhibit contrasting reactivities and will be described separately.

Dioctahedral smectites. Although reaction progress varies considerably as a function of the initial smectite sample, a similar effect was observed for all dioctahedral smectites. After 45 days, solution $\mathrm{pH}$ was not significantly modified, whereas the chemical composition of the solutions was altered (Table 2). In particular, the concentration in solution of alkali and alkaliearth cations which were initially present in smectite interlayers $\left(\mathrm{Na}^{+}, \mathrm{Ca}^{2+}\right.$, and $\left.\mathrm{K}^{+}\right)$was significantly increased after reaction (Table 2) together with that of silicon. For smectite samples reacted without metal iron, $\mathrm{Si}$ was not detected in solution, and the concentration in solution of alkali and alkali-earth cations after reaction was lower than in similar experiments performed in presence of metal iron (Table 2). In all reacted samples residual metal iron was systematically present together with newly-formed phases (magnetite and $7 \AA$ phyllosilicates - Figure 1a-e). However, iron particles observed in all reacted samples appear corroded as compared to their initial state (Figure 3a,b). In addition, clay particles with a distinct morphology were observed in all reacted samples (Figure 3c). These particles most likely correspond to the newly-formed phyllosilicate phase. Unreacted clay particles were also observed for both montmorillonite and beidellite samples (Figures 3d,e). Accordingly, residual smectite was identified for montmorillonite and beidellite samples from its $(02,11)$ 
band at $\sim 23^{\circ} 2 \theta \mathrm{CoK} \alpha$ (Figure 1a-d). The intensity of this characteristic band was much reduced after reaction for Garfield nontronite sample (Figure 1e), in agreement with the absence of unreacted clay particles in the reacted Garfield sample (Figure 3f).

Trioctahedral smectites. For saponite samples, solution $\mathrm{pH}$ and composition are not significantly modified after 45 days of iron-clay interactions (Table 2). Accordingly, XRD patterns recorded on both unreacted and reacted samples are alike (Figure 1f). In particular, the $(02,11)$ band $\left(\sim 23^{\circ} 2 \theta \mathrm{CoK} \alpha\right)$ is similar in both samples, an even the $(001)$ reflection $\left(\sim 7^{\circ} 2 \theta \mathrm{CoK} \alpha\right)$ is practically unaffected. In addition, no extra reflection was visible after reaction. SEM observations support this lack of reactivity as both iron (not shown) and clay particles (Figures 3g,h) appear unaltered after 45 days.

\section{Quantification of the extent of smectite destabilization}

A quantitative estimate of the relative proportion of smectite destabilized after reaction was obtained from XRD results using the internal standard method (Hillier, 2000). Results of this quantification are presented in Table 1 . The absolute precision on the relative proportion of smectite destabilized was estimated to be $\pm 10 \%$. This estimate corresponds to the standard deviation of twelve measurements obtained for 45 day experiments performed with sample SWy-2.

Using this quantitative XRD method it was possible to demonstrate the reactivity contrast as a function of the nature of initial smectite samples. For the different smectites presented in Figure 1, the relative proportion of destabilized smectite scatters indeed from 095\%. Trioctahedral smectites (SapCa-2 and SapFe08 samples) were essentially unaffected as a result of their interactions with iron, while the dioctahedral smectites were systematically destabilized. Montmorillonite (20 and 50\% of destabilized smectite for SAz-1 sample and 
SWy-2 samples, respectively) and beidellites (40, 60 and 70\% of destabilized smectite for CP4, SbId, and Drayton samples, respectively) were less destabilized than ferruginous smectites or nontronites (90 and $95 \%$ of destabilized smectite for SWa-1 and Garfield samples, respectively).

These quantification results were positively correlated to the estimates made using CEC measurements (Figure 4a). The precision of the CEC determination $( \pm 10 \%)$, which corresponds to the standard deviation of six measurements obtained for 45 day experiments performed with sample SWy-2, is similar to that of the XRD method. A good correlation was also obtained with the IR quantification results except for the Drayton sample (Figure 4b) which contains a significant proportion of ferric iron $\left(0.47\right.$ per $\mathrm{O}_{10}(\mathrm{OH})_{2}-$ Table 1). Precision was estimated from the standard deviation of six measurements obtained for 45 day experiments performed with sample SWy-2. IR measurements of reaction progress were found to be less precise ( $\pm 15 \%)$ than those using XRD and CEC methods mostly as a result of the uncertainty on the baseline determination. In addition, note that IR results obtained on raw materials may be correlated with XRD data only in the absence of kaolinite which exhibits a band at $911 \mathrm{~cm}^{-1}$ which may interfere with the Al-Al-OH, Al-Fe-OH and $\mathrm{Al}-\mathrm{Mg}-\mathrm{OH}$ vibration modes.

For the three quantification methods, the possible influence of the newly-formed clay phases was neglected. This approximation was justified by the nature (crondstedtite, odinite) of the newly-formed phases (Lantenois, 2003; Lantenois et al., 2005). These 1:1 phyllosilicates were indeed non-swelling species thus exhibiting an extremely low CEC. In addition, these phases include a large amount of structural iron. As a result, the $(02,11)$ band of these iron-rich 1:1 phyllosilicates was significantly shifted towards lower angles (at $\sim 4.7 \AA$ ) as compared to the $(02,11)$ band of initial smectite samples (at $4.45-4.56 \AA$ for the whole compositional range). In addition the intensity of the $(02,11)$ band of these iron-rich 1:1 
phyllosilicates was found to be extremely low, thus not affecting significantly the XRD measurements (Lantenois, 2003; Lantenois et al., 2005). The $\mathrm{OH}$ bending bands observed for these iron-rich 1:1 phyllosilicates were also shifted towards lower frequencies $\left(750-800 \mathrm{~cm}^{-1}\right.$ - Lantenois, 2003; Lantenois et al., 2005) as compared to initial Al-rich smectites (820$\left.940 \mathrm{~cm}^{-1}\right)$.

Kinetics of smectite destabilization

XRD quantification of the relative proportion of smectite destabilized after reaction also allowed deriving the kinetics of this destabilization reaction. For example, XRD patterns obtained for samples SbId reacted for 0, 5, 15, 30 and 45 days are presented in Figure 5. These experimental patterns are normalized to the (012) reflection of corundum so that the relative intensity of the $(02,11)$ band can be compared for all samples. The relative proportion of smectite destabilized was estimated from the intensity decrease of this $(02,11)$ band as a function of reaction time (0-120 days). Results are plotted in Figure 6 for four samples (SbId, Garfield, SWy-2 and SapCa-2). As described qualitatively, no reaction was observed for sample SapCa-2. For dioctahedral smectites, the relative proportion of destabilized smectite increases with time to reach a steady-state plateau after 30-45 days. The amount of destabilized smectite obtained after 45 days can be considered as the final one for all smectites. As was qualitatively observed the extent of smectite destabilization varies significantly as a function of the initial samples $(50 \%, 60 \%$ and $95 \%$ of destabilized smectite for the SWy-2, SbId and Garfield samples, respectively) 
Quantification by XRD of the relative proportion of destabilized smectite allowed

\section{Influence of $\mathrm{pH}$ on smectite destabilization}

The initial solution $\mathrm{pH}$, which is obtained by equilibrating the different smectite samples in water, depends on the nature of the smectite, and varies from 7.5-10.5 (SbId-1 and SWy-2, respectively - Table 2). To assess the impact of this parameter on reaction progress, the relative proportion of destabilized smectite was determined as a function of the initial $\mathrm{pH}$ for sample $\mathrm{SWy}-2$. Initial $\mathrm{pH}$ was adjusted by adding $\mathrm{HCl}$ or $\mathrm{NaOH}$ to the initial mixture. Relative proportion of destabilized smectite is reported in Table 3 . When initial $\mathrm{pH}$ is basic (8-12 $\mathrm{pH}$ range), the nature of the reaction products and the reaction progress are independent on $\mathrm{pH}$ (Table 3). Conversely, reaction is dramatically different when initial $\mathrm{pH}$ is mildly acidic to neutral. In such case, a large proportion of metal iron is dissolved, whereas iron oxides, identified as magnetite using XRD (data not shown), precipitate extensively. In addition, smectite appears unaffected (Table 3). A similar reaction, with the precipitation of magnetite and the stability of smectite, was observed for SapCa-2 and Garfield samples when initial $\mathrm{pH}$ was mildly acidic to neutral (Table 3 ). 
$340(\mathrm{pH}=6)$, smectite remains unaltered in presence of metal iron whatever its nature. However, smectite plays a catalytic role as in the same experimental conditions ( 45 days, $80^{\circ} \mathrm{C}$, initial $\mathrm{pH}=6)$ metal iron is not destabilized in the absence of smectite whereas in presence of smectite metal iron is oxidized, most likely from its interaction with solution protons, to form magnetite according to the following reaction:

$$
\begin{gathered}
\mathrm{Fe}^{\circ}+2 \mathrm{H}^{+} \rightarrow \mathrm{Fe}^{2+}+\mathrm{H}_{2}(\times 3) \\
2 \mathrm{Fe}^{2+}+2 \mathrm{H}^{+} \rightarrow 2 \mathrm{Fe}^{3+}+\mathrm{H}_{2} \\
\mathrm{Fe}^{2+}+2 \mathrm{Fe}^{3+}+4 \mathrm{H}_{2} \mathrm{O} \rightarrow \mathrm{Fe}_{3} \mathrm{O}_{4}+8 \mathrm{H}^{+} \\
3 \mathrm{Fe}^{\circ}+4 \mathrm{H}_{2} \mathrm{O} \rightarrow \mathrm{Fe}_{3} \mathrm{O}_{4}+4 \mathrm{H}_{2}
\end{gathered}
$$

In our experiments, the production of gaseous $\mathrm{H}_{2}$ during the reaction was not observed as Nalgene ${ }^{\circledR}$ reactors were $\mathrm{H}_{2}$ porous.

Under more basic $\mathrm{pH}$ conditions $(\mathrm{pH}>7$ obtained from the addition of $\mathrm{NaOH}$ if necessary), the reaction is dramatically different as dioctahedral smectites are involved in the reaction. Dioctahedral smectites are then destabilized to form new clay phases according to the following reaction:

$$
\text { Metal iron }+ \text { smectite } \rightarrow \text { 1:1 iron-rich phyllosilicate }+ \text { iron oxides }
$$

Under these basic $\mathrm{pH}$ conditions, destabilization of dioctahedral smectite is systematic but the amount of destabilized smectite varies significantly from one sample to the other most likely as a function of the initial smectite crystal chemistry. Note that except for Ksaturated smectites the equilibration $\mathrm{pH}$ of smectite with water is basic. The $\mathrm{pH}$ is essentially unaffected by iron-clay interactions. 
Influence of the di- or tri-octahedral character. Although initial $\mathrm{pH}$ values are alike, and basic, for both di- and tri-octahedral smectites, the reactivity of trioctahedral smectites is strikingly different from that of dioctahedral ones. Dioctahedral smectites are indeed systematically destabilized as the result of their interaction with metal iron whereas trioctahedral smectites remain unaffected under similar experimental conditions (Figures 1, 6). This lack of reactivity is independent on the iron content of trioctahedral smectites and on the nature of the interlayer cation.

Influence of structural $\mathrm{Fe}^{3+}$. As can be seen in Figure 6 and in Table 1, nontronite and ferruginous smectites are thoroughly destabilized as the result of their interaction with metal iron. In both cases, $\mathrm{Fe}^{3+}$ is the predominant cation in the octahedral sheet of these $2: 1$ expandable phyllosilicates which exhibit mostly tetrahedral substitutions (Table 1). By contrast, the extent of the destabilization is much reduced for smectites that are not iron-rich, whatever the origin of the layer charge deficit. However, this decrease of reactivity is less important for beidellites (tetrahedral layer charge) than for montmorillonites (octahedral layer charge) for a given $\mathrm{Fe}^{3+}$ content. To illustrate further the influence of the amount of structural iron on smectite destabilization, XRD patterns of reacted and unreacted samples are compared in Figures 1 and 7 for dioctahedral smectites with predominant tetrahedral charges (beidellites). Their octahedral $\mathrm{Fe}^{3+}$ content which ranges from 0.0-1.9 per $\mathrm{O}_{10}(\mathrm{OH})_{2}$. Relative proportions of destabilized smectites are reported as a function of the $\mathrm{Fe}^{3+}$ content in Figure 8. No reaction is observed when no structural $\mathrm{Fe}^{3+}$ is present in dioctahedral smectites, and smectite is not destabilized (Figures $7 \mathrm{a}, 8$ ). The presence of structural $\mathrm{Fe}^{3+}$ is thus an essential condition for the destabilization of dioctahedral smectites when in contact with metal iron. The minimum amount of structural $\mathrm{Fe}^{3+}$ necessary to induce this destabilization is extremely 
low as $60 \%$ of samples SbId is destabilized after 45 days of reaction with metal iron, in spite of its limited $\mathrm{Fe}^{3+}$ content $\left(0.1\right.$ atom per $\left.\mathrm{O}_{10}(\mathrm{OH})_{2}\right)$. In addition to this essential triggering role, the reactivity of dioctahedral smectite is clearly enhanced by an increased content of octahedral $\mathrm{Fe}^{3+}$ (Figure 8 ). However, this parameter is not the only structural parameter influencing smectite reactivity as, for example, the relative proportion of destabilized smectite is much higher for sample SbId than for sample CP4, in spite of the higher $\mathrm{Fe}^{3+}$ content in the latter sample (Figures 1c,d, 8 - Table 1).

Influence of the interlayer cation composition. The cation composition of smectite interlayers appears as an additional parameter influencing the reactivity of dioctahedral smectites. All samples used in the experiments reported to this point were unprocessed, and $\mathrm{Ca}^{2+}$ was usually predominant in their interlayer spaces (Table 1). However, $\mathrm{K}^{+}$was also present in $\mathrm{CP} 4$ and SbId, whereas $\mathrm{Na}^{+}$was present in several samples (SbId, SWy-2, SAz-1), and $\mathrm{Mg}^{2+}$ in Drayton sample. To assess the influence of the interlayer cation composition on smectite reactivity, three smectite samples (SWy-2, SAz-1 and Garfield) were reacted with metal iron following their saturation with $\mathrm{Na}^{+}, \mathrm{Ca}^{2+}$, and $\mathrm{K}^{+}$. XRD patterns of reacted $\mathrm{SWy}-2$ samples are presented in Figure 9, whereas the relative proportions of smectite destabilized after 45 days of reaction with metal iron are reported in Table 4. If Ca-saturated smectites are used as a reference, smectite destabilization is enhanced for Na-saturated smectites whereas it is decreased for K-saturated samples.

The reactivity contrast observed as a function of the interlayer cation composition is most likely related to the hydration of smectite which varies as a function of the interlayer cation (Norrish, 1954; Pons et al., 1981). The $\mathrm{d}_{(001)}$ basal spacing of $\mathrm{K}^{+}$-saturated smectites varies indeed from 12.5-15.5 $\AA$ in aqueous solution (Mamy, 1968; Besson and Tchoubar, 1980), whereas that of $\mathrm{Ca}^{2+}$-saturated smectites is 18.6-19.2 $\AA$ (Suquet, 1978). The $\mathrm{d}_{(001)}$ basal spacing of $\mathrm{Na}^{+}$-saturated smectites is not limited (osmotic swelling - Suquet et al., 1981). No 
significant collapse of smectite interlayers is expected as the ionic strength of the solutions, and more specifically the concentration of alkali and alkali-earth cations, remains low after reaction (Table 2). The enhanced reactivity observed for the most hydrated samples $\left(\mathrm{Na}^{+}>\right.$ $\mathrm{Ca}^{2+}>\mathrm{K}^{+}$) indicates that the ability of solution cations to access smectite interlayers is a key parameter to smectite destabilization.

Accordingly, the interlayer cation composition of samples CP4 ad SbId is likely responsible for their contrasting reactivity which does not seem to be consistent with their respective $\mathrm{Fe}^{3+}$ contents (Figure 8, Table 1). Specifically, the presence of $\mathrm{Na}^{+}$in the interlayers of sample SbId most likely enhances its reactivity as compared to sample CP4 in spite of the higher iron content in the latter sample. The influence of the cation interlayer composition may also account for the different reactivity exhibited by populations of particles observed in sample CP4. Using TEM-EDX, two populations of particles were indeed differentiated from their morphology, as "rolled" and "flat" particles were identified in this sample (Figure 10). The chemical analysis of these two types of particles revealed that although the composition of the 2:1 layers was identical in both cases, the two populations differed by their interlayer cation composition as the following structural formulae were derived for "rolled" and "flat" particles, respectively (average values from twelve analyses):

$$
\begin{aligned}
& \left(\mathrm{Ca}_{0.18} \mathrm{~K}_{0.03}\right)\left[\mathrm{Fe}^{(\mathrm{III})}{ }_{0.28} \mathrm{Al}_{1.72}\right]\left[\mathrm{Si}_{3.60} \mathrm{Al}_{0.40}\right] \mathrm{O}_{10}(\mathrm{OH})_{2} \\
& \left(\mathrm{Ca}_{0.13} \mathrm{~K}_{0.13}\right)\left[\mathrm{Fe}^{(\mathrm{III})}{ }_{0.31} \mathrm{Al}_{1.69}\right]\left[\mathrm{Si}_{3.60} \mathrm{Al}_{0.40}\right] \mathrm{O}_{10}(\mathrm{OH})_{2}
\end{aligned}
$$

After reaction with metal iron, no remnant "rolled" particles were observed and only "flat" particles persisted. This is likely due to the increased proportion of $\mathrm{K}^{+}$in the interlayer of the latter particles which reduces their reactivity. Note that because long-term experiments were not performed on homoionic samples, it is not clear if the relative proportion of smectite ultimately destabilized varies from one cation to the other, or if the nature of the interlayer cation essentially influences the destabilization rate. 
Towards a possible model for smectite destabilization

Experimental constrains. From the above observations, several structural features appear as

441

442

443

444

445

446

essential to the destabilization of smectite when in contact with metal iron. First, the smectite should be dioctahedral and should contain octahedral $\mathrm{Fe}^{3+}$. In addition, the accessibility of its interlayer space is a key parameter for the apparent reactivity of the dioctahedral smectite. Finally, when comparing experiments run at different $\mathrm{pH}$ values, structural protons of the smectite are likely involved in the oxidation of metal iron under neutral-to-alkaline conditions. In mildly acidic to neutral conditions, solution protons are abundant enough so that smectite is used essentially as a catalyst but is not directly involved in the corrosion of iron following Reaction (3). Under high $\mathrm{pH}$ conditions, protons are essentially present as $\mathrm{OH}$ groups in smectite, as both smectite interlayer and edge sites are essentially deprotonated under such $\mathrm{pH}$ conditions.

Deprotonation of these hydroxyl groups may occur under a variety of physicochemical conditions for dioctahedral smectites (Russel, 1979; Jaymes and Bigham, 1987; Heller-Kallai and Rozenson, 1981; Heller-Kallai, 2001 - Figure 11a). In particular, the presence of inorganic proton acceptors, usually alkali halides or alkali hydroxides, has been reported to induce such a deprotonation reaction (Heller-Kallai, 1975a, 1975b, 2001; Russel, 1979; Heller-Kallai and Rozenson, 1981; Heller-Kallai and Mosser, 1995). In our case, metal iron is likely the proton acceptor triggering smectite deprotonation. Metal iron is oxidized in turn as the result of its interaction with protons (Figure 11b) according to Reaction (3). The high affinity of metal iron for smectite and their resulting interactions have for example been recognized as causing the oxidation of steel pipes when using clay-containing drilling fluids (Tomoe et al., 1999; Cosultchi et al., 2003). According to this model, both the oxidation of 
metal iron and the deprotonation of smectite are strongly favored by the accessibility of metal iron to smectite interlayer. With this respect the osmotic swelling commonly observed for Nasaturated smectites significantly enhances the accessibility of metal iron particles to smectite interlayers, thus favoring the deprotonation reaction. In turn, deprotonation increases considerably the layer charge deficit in smectite octahedral sheet and thus enhances their reactivity.

Deprotonation thus appears as the driving force for the oxidation of metal ion, and for the initiation of smectite destabilization. Accordingly, the presence of $\mathrm{Fe}^{3+}$ in the octahedral sheet of smectite appears as an essential parameter for these two reactions as $\mathrm{MeFe}^{3+} \mathrm{OH}$ groups are known to deprotonate preferentially in dioctahedral smectites (Heller-Kallai, 1975a, 2001; Russel, 1979; Jaymes and Bigham, 1987). It is not clear however if deprotonation of $\mathrm{Fe}^{3+}$-free dioctahedral smectites is not occurring, or is extremely limited, or if deprotonation is not the limiting step for the destabilization of $\mathrm{Fe}^{3+}$-free dioctahedral smectites. However, although Heller-Kallai (1975a) showed that deprotonation occurs even in $\mathrm{Fe}^{3+}$-free dioctahedral smectite, we have not observed iron corrosion resulting from this process in the SbS-1 experiments.

Destabilization of smectite. Following its initial deprotonation, destabilization of smectite is probably favored by the presence of $\mathrm{Fe}^{2+}$ in solution as a result of the oxidation of metal iron. Specifically, the high affinity of $\mathrm{Fe}^{2+}$ for smectite edge surface sites (Tournassat et al., 2005 Figure 11c) is likely a key factor for the subsequent destabilization of smectite. Following their sorption on these edge sites, $\mathrm{Fe}^{2+}$ cations are readily oxidized as shown by Tournassat $e t$ al. (2005), the electron acceptors being octahedral $\mathrm{Fe}^{3+}$ from smectite structure (Figure 11c). Note that following their oxidation, sorbed Fe cations may also accept electrons either from solution $\mathrm{Fe}^{2+}$ cations or from iron metal to restore their $+\mathrm{II}$ valency (Figure 11d). As a result of both its initial deprotonation and of the subsequent reduction of its structural $\mathrm{Fe}^{3+}$, the 
charge deficit in the octahedral sheet of smectite is dramatically increased and $\mathrm{Fe}^{2+}$ cations likely migrate in its interlayers to compensate for the increased layer charge (Figure 11d). The inceased concentration of $\mathrm{Fe}^{2+}$ in solution resulting from the oxidation of the metal iron also favors a $\mathrm{Fe}^{2+}$-for- $\mathrm{Na}^{+}$cation exchange. Such $\mathrm{Fe}^{2+}$-for- $\mathrm{Na}^{+}$cation exchange has been shown to occur in reducing environments cations (Kamei et al., 1999).

The effective ionic radius of $\mathrm{Fe}^{2+}$ cations $(0.78 \AA$ - Shannon, 1976) is smaller than the limit size approximated by Heller-Kallai (2001) at $0.85 \AA$ allowing migration of the cations into the silicate layer. It is thus likely that interlayer $\mathrm{Fe}^{2+}$ cations actually migrate either into the di-trigonal cavities of smectite tetrahedral sheets or in smectite octahedral sheet (Figure 11e). This migration is similar to that of $\mathrm{Li}^{+}$cations $(0.76 \AA$ - Shannon, 1976) involved in the Hofmann-Klemen test (Hofmann and Klemen, 1950; Greene-Kelly, 1955). The migration of $\mathrm{Li}^{+}$from the interlayer to the di-trigonal cavity and further to the octahedral sheet of montmorillonites has been extensively documented (Hofmann and Klemen, 1950; GreeneKelly, 1955 ; Glaeser and Fripiat, 1976; Madejova et al., 1996, 2000a, 2000b, among others). Heating to $300^{\circ} \mathrm{C}$ for 24 hours represent optimum experimental conditions for this migration. Migration of other divalent cations with an effective ionic radius similar to that of $\mathrm{Li}^{+}$cations has also been described. For example, $\mathrm{Cu}^{2+}, \mathrm{Ni}^{2+}$ and $\mathrm{Zn}^{2+}$ cations $(0.73,0.69$ and $0.74 \AA$, respectively) migrate from montmorillonite interlayers to the di-trigonal cavity between 100 $300^{\circ} \mathrm{C}$ (Heller-Kallai and Mosser, 1995; Mosser et al., 1997; Madejova et al., 1999; Palkova et al., 2003) and to the octahedral sheet at higher temperature (Brindley and Ertem, 1971; McBride and Mortland, 1974; Heller-Kallai and Mosser, 1995; Emmerich et al., 1999).

These conditions are much more energetically favorable than those involved in our experiments. However, partial migration of $\mathrm{Li}$ at least to the di-trigonal cavity has been reported for Li-saturated montmorillonite heated to $105^{\circ} \mathrm{C}$ for 24 hours (Madejova et al., 1996). In our experiments, three factors compensate for the low thermal energy available. The 
first one is the extremely strong layer charge deficit which, according to the structural model proposed for smectite destabilization occurring in our experiments, arises both from the deprotonation of hydroxyl groups and from the reduction of structural $\mathrm{Fe}^{3+}$. Note that the need for an octahedral layer charge deficit is the fundamental basis for the migration of $\mathrm{Li}^{+}$cations involved in the Hofmann-Klemen test (Hofmann and Klemen, 1950). Furthermore, the positive influence of an increased layer charge deficit on the migration of divalent cations has been reported by Heller-Kallai and Mosser (1995, e.g.). These authors observed indeed an increased amount of $\mathrm{Cu}$ in samples that were deprotonated first. As described by Heller-Kallai and Mosser (1995), the positive effect of the initial deprotonation is not restricted to the increased layer charge deficit and the second factor favoring the migration of $\mathrm{Fe}^{2+}$ cations is the absence of protons inside the di-trigonal cavity. As a consequence, there is no electrostatic repulsion to the migration of $\mathrm{Fe}^{2+}$ cations into the octahedral sheet. Reaction time represents the third factor compensating for the low thermal energy in our experiments. Our experiments lasted indeed for 45 days whereas the common duration of experiments leading to the formation of reduced-charge smectites is 24 hours. Initial migration of $\mathrm{Fe}^{2+}$ cations to the ditrigonal cavity is likely favored by an increased undersaturation of the oxygen atoms present at the surface of the 2:1 layers, that is by the existence of layer charge deficit in smectite tetrahedral sheets. Such location of layer charge deficit favors indeed the initial partial dehydration of interlayer $\mathrm{Fe}^{2+}$ cations, allowing for the formation of an inner-sphere complex necessary for their migration, and thus accounts for the increased reactivity of beidellite samples as compared to montmorillonite ones for a given iron content (see for example SAz-1 and SbId samples - Table 1). The formation of such inner-sphere complexes has been widely documented in hydrated beidellites for monovalent interlayer cations, both from XRD (Ben Brahim et al., 1983a, 1983b, 1984), and infrared (Pelletier et al., 2003) studies, and from Monte-Carlo modeling (Chang et al., 1995; Skipper et al., 1995). 
In our experiments, migration of $\mathrm{Fe}^{2+}$ cations in the octahedral sheet of smectite does

538 not induce a collapse of smectite interlayers as these new octahedral $\mathrm{Fe}^{2+}$ compensate essentially for the layer charge deficit resulting from the deprotonation of hydroxyl groups and from the reduction of structural $\mathrm{Fe}^{3+}$, but not for the initial charge deficit of the 2:1 layers. The presence of hydrated interlayer cations, part of which are $\mathrm{Fe}^{2+}$, still compensates for this initial charge deficit, and keeps the smectite interlayers expanded. The migration of $\mathrm{Fe}^{2+}$ cations in the octahedral sheet of smectite is rather thought to be responsible for the destabilization of smectites induced by their interaction with metal iron. Destabilization is indeed thought to result from the presence of trioctahedral domains in the octahedral sheet of reacted smectite (Figure 11e). The coexistence of both dioctahedral and trioctahedral domains is widely reported in natural 1:1 phyllosilicates but is limited in 2:1 phyllosilicates (Bailey, 1980). The existence of 2:1 phyllosilicates with a mixed di- and tri-octahedral occupancy is indeed essentially limited to mica species exhibiting a tetrahedral charge (muscovitezinnwaldite or muscovite-phlogopite series - Monier and Robert, 1986). In such species the increased dimensions of the octahedral sheet in the ab plane is accommodated by the reduction of the tetrahedral tilt angle. In smectites, and more especially in montmorillonites, the amount of tetrahedral substitutions is limited and the tetrahedral tilt angle is thus minimum. As a consequence, such 2:1 phyllosilicates are unable to accommodate the presence of trioctahedral domains containing large cations and are thus destabilized by the migration of $\mathrm{Fe}^{2+}$ cations in their octahedral sheet.

According to the conceptual model hypothesized for smectite destabilization, the lack of reactivity of trioctahedral smectites results from three main factors. The first two are related to the absence of $\mathrm{Fe}^{3+}$ cations in the octahedral sheet of these smectite samples. The first effect of this absence is to make deprotonation of hydroxyl groups more difficult as, in dioctahedral smectites, $\mathrm{MeFe}^{3+} \mathrm{OH}$ groups are known to deprotonate preferentially (Heller- 
Kallai, 1975a, 2001; Russel, 1979; Jaymes and Bigham, 1987). The second effect is the absence of cations that may be reduced in the octahedral sheet of trioctahedral smectites. The combination of these two effects prevents building a strong layer charge deficit in the octahedral sheet of trioctahedral smectites. The third factor leading to the lack of reactivity of trioctahedral smectite is the obvious impossibility for cations to migrate in this octahedral sheet which is fully occupied.

Influence of structural Fe on smectite destabilization. In the above conceptual model for smectite destabilization, the effect of an increased proportion of structural iron on smectite destabilization is dual. The first effect arises from the increased proportion of $\mathrm{MeFe}^{3+} \mathrm{OH}$ groups that will readily deprotonate when in contact with metal iron. The larger number of deprotonated hydroxyl groups requires in turn the presence of a larger number of $\mathrm{Fe}^{2+}$ cations in smectite interlayers to balance the charge. The second effect is directly related to the increased proportion of structural $\mathrm{Fe}^{3+}$ in smectite octahedral sheet. This allows for a larger proportion of smectite octahedral sheets to present dramatic charge deficit leading to the migration of interlayer $\mathrm{Fe}^{2+}$ in the 2:1 layer, thus destabilizing it. On the other hand, the presence of $\mathrm{Fe}^{3+}$ in smectite tetrahedral sheet does not enhance smectite reactivity as these cations cannot be reduced because of steric constrains arising from their tetrahedral environment.

\section{CONCLUSION}

The present study aimed at assessing the stability of smectites, which represent the reactive components of engineered and geological barriers, when in contact with metal iron at temperatures realistic in the context of nuclear waste disposal $\left(80^{\circ} \mathrm{C}\right)$. Dioctahedral smectites are thoroughly destabilized under such conditions, leading to the precipitation of magnetite 
and of 1:1 iron-rich phyllosilicates [odinite, crondstedtite - Lantenois (2003), Lantenois et al. (2005)]. Smectite destabilization is systematic for neutral-to-basic $\mathrm{pH}$ conditions $(\mathrm{pH}>7)$, whereas in mildly acidic to neutral $\mathrm{pH}$ conditions, a significant proportion of metal iron is corroded to form magnetite without smectite destabilization.

An XRD method was developed to quantify the extent of smectite destabilization. This method was validated against CEC measurements and IR spectroscopy results. Structural and crystal-chemical factors favoring smectite destabilization were thus determined. These parameters include the amount of octahedral iron, the presence of tetrahedral substitutions, and the nature of interlayer cations, and a conceptual model was hypothesized to account for smectite destabilization. According to this model, the formation of trioctahedral clusters resulting from the migration of $\mathrm{Fe}^{2+}$ cations into the octahedral sheet of the 2:1 layer is responsible for smectite destabilization as tetrahedral sheets are unable to accommodate the larger dimensions of these domains.

In agreement with experimental results, the dioctahedral character of the initial smectite is an essential condition for its destabilization in the proposed model. As a result the non-reactivity of trioctahedral smectites appears as an important point for the conception of engineered barriers for nuclear waste disposal, although natural deposits of trioctahedral smectite are uncommon.

\section{ACKNOWLEDGMENTS}

J.-L. Robert is thanked for the insightful discussions which allowed improving the present manuscript. The precious help of R. Champallier and J.-L. Robert, who prepared the synthetic smectite samples, and of W.P. Gates, who provided us with the CP4 and Drayton Fe-beidellites, is gratefully acknowledged. J.-M. Bény and P. Benoist (I.S.T. Orléans) are 
thanked for their assistance during infrared spectroscopy and CEC measurements, respectively. The present manuscript was improved by the constructive reviews of Lisa Heller-Kallaï, Will P. Gates and AE Peter Komadel.

Aogaki, R. (1999) Non-equilibrium fluctuations in the corrosion. pp 217-305 in: Modern aspects of electrochemistry (R.E White, B.E. Conway and J.O'M. Bockris editors). Kluwer, New York.

Bailey, S.W. (1980) Structures of layer silicates. pp. 1-123 in Crystal Structures of Clay Minerals and their X-ray Identification (G.W. Brindley and G. Brown editors). Mineralogical Society, London.

Ben Brahim, J., Armagan, G., Besson, G. and Tchoubar, C. (1983a) X-ray diffraction studies on the arrangement of water molecules in a smectite. I. Homogeneous two-water-layer Na-beidellite. Journal of Applied Crystallography, 16, 264-269.

Ben Brahim, J., Besson, G. and Tchoubar, C. (1983b) Layer succession and water molecules arrangement in a homogeneous two-water layer Na-smectite. Pp. 65-75 in: Proceedings of the 5th Meeting of the European Clay Groups, Prague.

Ben Brahim, J., Besson, G. and Tchoubar, C. (1984) Etude des profils des bandes de diffraction $\mathrm{X}$ d'une beidellite-Na hydratée à deux couches d'eau. détermination du mode d'empilement des feuillets et des sites occupés par l'eau. Journal of Applied Crystallography, 17, 179-188.

Besson, G. and Tchoubar, C. (1980) Exemple d'ordre-désordre par rotation des feuillets dans la montmorillonite potassique. Bulletin de Minéralogie, 103, 429-433. 
Brindley, G.W. and Ertem G. (1971) Preparation and solvation properties of some variable charge montmorillonites. Clays and Clay Minerals, 19, 399-404.

Chang, F.R.C., Skipper, N.T. and Sposito, G. (1995) Computer simulation of interlayer molecular structure in sodium montmorillonite hydrates. Langmuir, 11, 2734-2741.

Cosultchi, A., Rossbach, P. and Hernandez-Calderon, I. (2003) XPS analysis of petroleum well tubing adherence. Surface and Interface Analysis, 35, 239-245.

Cuadros, J. and Altaner, S.P. (1998) Compositional and structural features of the octahedral sheet in mixed-layer illite/smectite from bentonites. European Journal of Mineralogy, 10, $111-124$.

Emmerich, K., Madsen, F. T. and Kahr G. (1999) Dehydroxylation behavior of heat-treated and steam-treated homoionic cis-vacant montmorillonites. Clays and Clay Minerals, 47, 591-604.

Farmer, V.C. (1974) The IR Spectra of minerals. 539 p. Mineralogical Society, London.

Gaboriau, H. (1991) Interstratifiés smectite-kaolinite de l'Eure. Thesis, Université d'Orléans, $274 p$.

Gates, W.P., Slades, P.G., Manceau, A. and Lanson, B. (2002) Site occupancies by iron in nontronites. Clays and Clay Minerals, 50, 223-239.

Glaeser R. and Fripiat J. J. (1976) Hydratation des smectites et démixtion des cations Li, Na en fonction de la localisation des substitutions isomorphiques. Clay Minerals, 11, 9399.

Goodman, B.A., Russell, J.D., Fraser, A.R. and Woodhams, F.W.D. (1976) A mössbauer and I.R. spectroscopic study of the structure of nontronite. Clays and Clay Minerals, 24, 53-59.

Greene-Kelly, L. (1955) Dehydration of montmorillonite minerals. Mineralogical Magazine, 30, 604-615. 
Guillaume, D., Neaman, A., Cathelineau, M., Mosser-Ruck, R., Peiffert, C., Abdelmoula, M., Dubessy, J., Villieras, F., Baronnet, A. and Michau, N. (2003) Experimental synthesis of chlorite from smectite at $300^{\circ} \mathrm{C}$ in the presence of metallic Fe. Clay Minerals, 38, 281-302.

Habert, B. (2000) Réactivité du fer dans les gels et les smectites. Thesis, Université Paris 6, Paris, 227p.

Hamilton, D.L. and Henderson, C.M.B. (1968) The preparation of silicate compositions by a gelling method. Mineralogical Magazine, 36, 832-838.

Heller-Kallai, L. (1975a) Interaction of montmorillonite with alkali halides. S. W. Bailey (ed.) proceding of international clay conference, Mexico, p. 361-375.

Heller-Kallai, L. (1975b) Montmorillonite-alkali halide interaction : a possible mechanism of illitization. Clays and Clay Mineral, 23, 462-467.

Heller-Kallai, L. (2001) Protonation-deprotonation of dioctahedral smectites. Applied Clay Science, 20, 27-38.

Heller-Kallai, L. and Rozenson, I. (1981) Nontronite after acid or alkali attack. Chemical Geology, 32, 95-102.

Heller-Kallai, L. and Mosser, C. (1995) Migration of $\mathrm{Cu}$ ions in $\mathrm{Cu}$ montmorillonite heated with and without alkali halides. Clays and Clay Minerals, 43, 738-743.

Hillier, S. (2000) Accurate quantitative analysis of clay and other minerals in sandstones by XRD: comparison of a Rietveld and a reference intensity ratio (RIR) method and the importance of sample preparation. Clay Minerals, 35, 291-302.

Hofmann, V. and Klemen, R. (1950) Verlust der Austauschfähigkeit von lithiumionen aus Bentonit durch Erhitzung. Zeitschrift für Anorganische und Allgemeine Chemie, 262, 95-99. 
Jaymes, W. F. and Bigham, J. M. (1987) Charge reduction, octahedral charge, and lithium retention in heated, Li-saturated smectites. Clays and Clay Minerals, 35, 440-448.

Kamei, G., Oda, C., Mitsui, S., Shibata, M., Shinozaki, T. (1999) Fe(II)-Na ion exchange at interlayers of smectite : adsorption-desorption experiments and a natural analogue. Engineering Geology, 54, 15-20.

Kloprogge, J.T., Komarnene, S. and Amonette, J.E. (1999) Synthesis of smectite clay minerals: a critical review. Clays and Clay Minerals, 47, 529-554.

Kohler, E. (2001) Réactivité des mélanges synthétiques smectite/kaolinite et smectite/aluminium gel en présence d'un excès de fer métal. DRT, Université d'Evry val d'Essonne, Evry, 101p.

Lantenois, S. (2003). Réactivité fer métal/smectites en milieu hydraté à $80^{\circ} \mathrm{C}$. Ph.D. thesis, Université d'Orléans, Orléans, 188p

Lantenois, S., Lanson, B., van Aken, P. A., Jullien, M., Muller, F. and Plancon A. (2005) Experimental study of metal iron - smectites interactions at low temperature : characterisation of the newly-formed phases. Geochimica Et Cosmochimica Acta (in preparation).

Madejova, J. and Komadel, P. (2001) Baseline studies of the clay minerals society source clays: infrared methods. Clays and Clay Minerals, 49, 410-432.

Madejova, J., Arvaiova, B. and Komadel, P. (1999) FTIR spectroscopic characterization of thermally treated $\mathrm{Cu}^{2+}, \mathrm{Cd}^{2+}$ and $\mathrm{Li}^{+}$montmorillonites. Spectrochimica Acta Part A, $55,2467-2476$.

Madejova, J., Bujdak, J., Gates, W. P. and Komadel, P. (1996) Preparation and infrared spectroscopic characterization of reduced-charge montmorillonite with various $\mathrm{Li}$ contents. Clay Minerals, 31, 233-241. 
Madejova, J., Bujdak, J., Petit, S. and Komadel, P. (2000a) Effects of chemical composition and temperature of heating on the infrared spectra of Li-saturated dioctahedral smectites. (I) Mid-infrared region. Clay Minerals, 35, 739-751.

Madejova, J., Bujdak, J., Petit, S. and Komadel, P. (2000b) Effects of chemical composition and temperature of heating on the infrared spectra of Li-saturated dioctahedral smectites. (II) Near-infrared region. Clay Minerals, 35, 753-761.

Mamy, J. (1968) Recherches sur l'hydratation de la montmorillonite: Propriétés diélectriques et structure du film d'eau. Thesis, Université de Paris 6, Paris, 142p.

McBride, M.B. and Mortland M.M. (1974) Copper (II) interactions with montmorillonite: Evidence from physical methods. Soil Science Society of America Proceedings, 38, 408-415.

Monier, G., Robert, J.-L. (1986) Evolution of the miscibility gap between muscovite and biotite solid solutions with increasing lithium content : an experimental study in the system $\mathrm{K}_{2} \mathrm{O}-\mathrm{Li}_{2} \mathrm{O}-\mathrm{MgO}-\mathrm{FeO}-\mathrm{Al}_{2} \mathrm{O}_{3}-\mathrm{SiO}-\mathrm{H}_{2} \mathrm{O}-\mathrm{HF}$ at $600^{\circ} \mathrm{C}, 2$ kbar $p_{\mathrm{H} 2 \mathrm{O}}$ : comparison with natural lithium micas. Mineralogical Magazine, 50, 641-651.

Mosser, C., Michot, L. J., Villieras, F. and Romeo, M. (1997) Migration of cations in copper(II)-exchanged montmorillonite and laponite upon heating. Clays and Clay Minerals, 45, 789-802.

Norrish, K. (1954) The swelling of montmorillonite. Discussions of the Faraday Society, 18, $120-134$.

Palkova, H., Madejova, J. and Righi, D. (2003) Acid dissolution of reduced-charge Li- and Ni-montmorillonites. Clays and Clay Minerals, 51, 133-142.

Pelletier, M., Michot, L.J., Humbert, B., Barres, O., D'espinose de la Callerie, J.B. and Robert, J.L. (2003) Influence of layer charge on the hydroxyl stretching of 
trioctahedral clay minerals: A vibrational study of synthetic Na- and K-saponites. American Mineralogist, 88, 1801-1808.

Perronnet, M. (2001) Etude des interactions fer-argile en condition de stockage géologique profond des déchets nucléaires HAVL. DEA, ENS Géologie, Nancy, 33p.

Perronnet, M. (2004) Etude des interactions fer-argile en condition de stockage géologique profond des déchets nucléaires HAVL. Ph.D. thesis, ENS Géologie, Nancy, 233p.

Pons, C.H., Rousseaux, F. and Tchoubar, D. (1981) Utilisation du rayonnement synchrotron en diffusion aux petits angles pour l'étude du gonflement des smectites: I Etude du système eau-montmorillonite-Na en fonction de la température. Clay Minerals, 16, 2342.

Roux, J. and Volfinger, M. (1996) Mesures précises à l'aide d'un détecteur courbe. Journal de Physique, IV, 127-134.

Russell, J.D. (1979) An infrared spectroscopic study of the interaction of nontronite and ferruginous montmorillonites with alkali metal hydroxides. Clay Minerals, 14, 127137.

Russell, J. and Fraser, A. (1994) Infrared methods in Clay mineralogy: spectroscopic and chemical determinative methods. M.J. Wilson, Ed. Chapman and Hall, London, p. 1167.

Shannon, R. D. (1976) Revised effective ionic radii and systematic studies of interatomic distances in halides and chalcogenides. Acta Crystallographica A, 32, 751-767.

Skipper, N.T., Chang, F.R.C. and Sposito, G. (1995) Monte Carlo simulation of interlayer molecular structure in swelling clay minerals. 1. Methodology. Clays \& Clay Minerals, 43, 285-293.

Suquet, H.B. (1978) Propriétés de gonflement et structure de la saponite. Comparaison avec la vermiculite. Thesis, Université Pierre et Marie Curie, Paris, 175p. 
Suquet, H., Ilyama, J.T., Kodama, H. and Pezerat, H. (1977) Synthesis and swelling properties of saponites with increasing layer charge. Clays and Clay Minerals, 25, 231-242.

Suquet, H., Malard, C., Copin, E. and Pezerat, H. (1981) Variation du paramètre b et de la distance basale $\mathrm{d}_{001}$ dans une série de saponites à charge croissante: I Etats hydratés. Clay Minerals, 16, 53-67.

Tomoe, Y., Shimizu, M. and Nagae, Y. (1999) Unusual corrosion of a drill pipe in newly developed drilling mud during deep drilling. Corrosion, 55, 706-713.

Tournassat C., Charlet L. \& Greneche J.-M. Interactions of $\mathrm{Fe}^{2+}, \mathrm{Zn}^{2+}$, and $\mathrm{H}_{4} \mathrm{SiO}_{4}$ at clay/water interfaces: Distinguishing sorption, coadsorption, and surface oxidation phenomena. Geochimica and Cosmochimica Acta, submitted

Vantelon, D., Pelletier, M., Michot, L.J., Barres, O. and Thomas, F. (2001) Fe, Mg and Al distribution in the octahedral sheet of montmorillonites. An infrared study in the $\mathrm{OH}-$ bending region. Clay Minerals, 36, 369-379. 
Figure 1. XRD patterns obtained on unreacted and reacted smectite samples (upper and lower patterns, respectively). Montmorillonite, beidellite, nontronite and saponite samples were reacted for 45 days with metal iron at $80^{\circ} \mathrm{C}$ (see text for details) (a) Sample SWy-2 ,(b)

Sample SAz-1, (c) Sample SbId, (d) Sample CP4, (e) Sample Garfield, (f) Sample SapCa-2, and (g) Sample SapFe08. Scale factor (x3) over the $20-35^{\circ} 2 \theta$ CoK $\alpha$ range. Patterns were normalized by pairs to the integrated intensity of corundum (012) reflection (solid line, S).

The $(001)$ reflection and the $(02,11)$ band of the clay samples are labeled. Q indicates the presence of quartz impurities in some samples (dashed lines). Dotted lines indicate the reflections of newly-formed phases. These phases are labeled M, L, and P for magnetite $\left(\mathrm{Fe}_{3} \mathrm{O}_{4}\right)$, lepidocrocite $(\gamma-\mathrm{FeOOH})$, and a newly formed 1:1 phyllosilicate, respectively.

Figure 2. Method for quantifying the relative proportion of destabilized smectite using IR spectroscopy. (a) IR spectrum of sample SWy-2 (unreacted) before subtraction of the baseline. Si-O indicates the $\mathrm{Si}-\mathrm{O}$ vibrations in phyllosilicates whereas $\mathrm{Al}-\mathrm{Al}-\mathrm{OH}, \mathrm{Al}-\mathrm{Fe}-\mathrm{OH}$ and $\mathrm{Al}-\mathrm{Mg}-\mathrm{OH}$ refer to the $\mathrm{OH}$ bending mode of the respective hydroxyl groups. Q denotes the two vibrations bands of quartz. (b) Decomposition assuming three Guassian-shaped contributions of the $\mathrm{OH}$ bending zone after baseline subtraction (sample SWy-2 unreacted).

Figure 3. SEM micrographs of unreacted and reacted samples. Metal iron particles in unreacted and reacted SWy-2 sample are shown on (a) and (b), respectively. (c) and (d) Smectite particles in the reacted sample SWy-2. (e) Smectite particles in the initial sample SWy-2. (f) Smectite particles in the reacted Garfield sample. (g) Smectite particles in the initial sample SapCa-2. (h) Smectite particles in the reacted sample SapCa-2.

Figure 4. Relative proportion of destabilized smectite calculated by XRD and CEC methods (a) and by XRD and infrared methods (b). Solid square: sample SapCa-2; solid triangle: 
sample SAz-1; solid circle: sample SWy-2; solid diamond: Garfield sample; open diamond: Drayton sample. The (1:1) line is shown as a solid line.

Figure 5. XRD patterns obtained for unreacted SbId sample (a) and for reacted SbId sample (b-e). (b), (c), (d) and (e) correspond to 5, 15, 30 and 45 day experiments, respectively. Scale factor (x3) over the $20-35^{\circ} 2 \theta \mathrm{CoK} \alpha$ range. Patterns were normalized as in Figure 1. Other labels and patterns as in Figure 1.

Figure 6. Evolution of the relative proportion of destabilized smectite as a function of reaction time. Symbols as in Figure 4. Open triangles: sample SbId.

Figure 7. XRD patterns obtained on unreacted and reacted beidellite samples (upper and lower patterns, respectively). Patterns are ranked as a function of their structural $\mathrm{Fe}^{3+}$ content (Table 1). Samples were reacted for 45 days with metal iron at $80^{\circ} \mathrm{C}$ without controlling the initial pH. (a) Sample SbS-1, (b) Drayton sample, and (c) sample SWa-1. Scale factor (x3) over the $20-35^{\circ} 2 \theta \mathrm{CoK} \alpha$ range. Patterns were normalized as in Figure 1. Other labels and patterns as in Figure 1.

Figure 8. Relative proportion of destabilized smectite after reaction with metal iron as a function of their content of structural $\mathrm{Fe}^{3+}$ (Table 1) Relative proportion of destabilized smectite amounts was estimated using XRD on 45 day experiments.

Figure 9. XRD patterns recorded on sample SWy-2 reacted with metal iron after K-, Ca-, and Na-saturation (b, c, and d, respectively). Unreacted Na-saturated sample corresponds to the raw SWy-2 sample (a). Scale factor (x3) over the $20-35^{\circ} 2 \theta \mathrm{CoK} \alpha$ range. Patterns were normalized as in Figure 1. Other labels and patterns as in Figure 1.

Figure 10. Transmission electron micrographs of smectite particles from sample CP4. "rolled" and "flat" particles are labeled (1) and (2), respectively.

Figure 11. Conceptual model leading to the destabilization of dioctahedral smectites as a result of their interaction with metal iron. (a) Deprotonation of $\mathrm{MeFe}^{3+} \mathrm{OH}$ groups. (b) 
823 Oxidation of metal iron as a result of its interaction with released protons. (c) Sorption of $\mathrm{Fe}^{2+}$ 824 cations on the edges of smectite particles and reduction of structural $\mathrm{Fe}^{3+}$ cations. (d) 825 Migration of solution $\mathrm{Fe}^{2+}$ cations in smectite interlayers to compensate for the layer charge 826 deficit. Part of this migration results from a $\mathrm{Fe}^{2+}$-for- $\mathrm{Na}^{+}$exchange. With time, interlayer $\mathrm{Fe}^{2+}$ 827 cations migrate to the di-trigonal cavity and further to the octahedral sheet to compensate 828 locally for the charge deficit. (e) Coexistence of di- and tri-octahedral domains in the 829 octahedral sheet of smectite leads to its destabilization. 
Table 1: Chemical composition of the initial smectite materials (structural formulae calculated per $\mathrm{O}_{10}(\mathrm{OH})_{2}$ ) and relative proportion of smectite destabilized after reaction with metal iron for 45 days.

\begin{tabular}{|c|c|c|c|c|c|c|c|c|c|c|}
\hline Sample & Garfield $^{a}$ & SWa-1 ${ }^{a}$ & Drayton $^{b}$ & $\mathrm{CP} 4^{\mathrm{b}}$ & $\mathrm{Sbld}^{\mathrm{C}}$ & $\mathrm{SbS}-1^{\mathrm{c}, \mathrm{d}}$ & $S W y-2^{c}$ & SAz-1 ${ }^{\mathrm{C}}$ & SapCa-2 ${ }^{\mathrm{C}}$ & SapFe0 $8^{\mathrm{c}, \mathrm{d}}$ \\
\hline Nature ${ }^{\mathrm{e}}$ & $\mathrm{N}$ & FS & $\mathrm{B}$ & $\mathrm{B}$ & B & $\mathrm{B}$ & M & $\mathrm{M}$ & $\mathrm{S}$ & $S$ \\
\hline \multicolumn{11}{|l|}{ Tetrahedral } \\
\hline $\mathrm{Si}$ & 3.51 & 3.70 & 3.69 & 3.60 & 3.71 & 3.66 & 3.95 & 4.00 & 3.58 & 3.62 \\
\hline Al & 0.49 & 0.30 & 0.31 & 0.40 & 0.29 & 0.34 & 0.05 & - & 0.39 & - \\
\hline $\mathrm{Fe}^{3+}$ & - & - & - & - & - & - & - & - & 0.03 & 0.38 \\
\hline charge & -0.49 & -0.30 & -0.31 & -0.40 & -0.29 & -0.34 & -0.05 & - & -0.42 & -0.38 \\
\hline \multicolumn{11}{|l|}{ Octahedral } \\
\hline Al & 0.11 & 0.55 & 1.11 & 1.70 & 1.80 & 2.00 & 1.56 & 1.37 & - & - \\
\hline $\mathrm{Fe}^{3+}$ & 1.86 & 1.31 & 0.47 & 0.30 & 0.12 & - & 0.21 & 0.07 & - & 0.00 \\
\hline $\mathrm{Mg}$ & 0.02 & 0.13 & 0.44 & - & 0.08 & - & 0.23 & 0.56 & 3.00 & 3.00 \\
\hline occupancy & 1.99 & 1.99 & 2.02 & 2.00 & 2.00 & 2.00 & 2.00 & 2.00 & 3.00 & 3.00 \\
\hline charge & -0.05 & -0.16 & -0.38 & 0.00 & -0.08 & 0.00 & -0.23 & -0.56 & 0.00 & 0.00 \\
\hline \multicolumn{11}{|l|}{ Interlayer } \\
\hline $\mathrm{Na}$ & 0.09 & 0.03 & - & - & 0.08 & 0.33 & 0.14 & 0.05 & 0.34 & 0.39 \\
\hline $\mathrm{Ca}$ & 0.20 & 0.20 & 0.17 & 0.15 & 0.10 & - & 0.05 & 0.24 & 0.05 & - \\
\hline $\mathrm{Mg}$ & - & - & 0.18 & - & - & - & - & - & - & - \\
\hline $\mathrm{K}$ & 0.04 & 0.05 & - & 0.09 & 0.08 & - & 0.01 & 0.01 & 0.02 & - \\
\hline charge & 0.53 & 0.48 & 0.70 & 0.39 & 0.36 & 0.33 & 0.25 & 0.54 & 0.46 & 0.39 \\
\hline $\begin{array}{l}\text { Smectite } \\
\text { destab. } \\
\text { (wt \%) }\end{array}$ & 95 & 90 & 70 & 40 & 60 & 0 & 50 & 20 & 0 & 0 \\
\hline $\begin{array}{l}\text { Note: }{ }^{a} \text { From } \\
\text { EDX analysis } \\
\text { correspond tc }\end{array}$ & set a & $\begin{array}{l}\text { D). Ir } \\
\text { on el }\end{array}$ & er cor & $\begin{array}{l}\text { ion of } \\
\text {, ele }\end{array}$ & nate & $\begin{array}{l}\text { as det } \\
\text { e analy }\end{array}$ & $\begin{array}{l}\text { ned fro } \\
\text { synth }\end{array}$ & $\begin{array}{l}\text { ectron } \\
\text { clays. }\end{array}$ & $\begin{array}{l}\text { croprobe a } \\
\text { J, FS, B, N }\end{array}$ & alysis, ${ }^{b}$ \\
\hline
\end{tabular}


Table 2: Chemical composition of the solution after reaction of smectite samples with metal iron for 45 days.

\begin{tabular}{cccccccccc}
\hline & $\mathrm{Si}$ & $\mathrm{Al}$ & $\mathrm{Fe}$ & $\mathrm{Mg}$ & $\mathrm{Na}$ & $\mathrm{Ca}$ & $\mathrm{K}$ & Initial $\mathrm{pH}$ & Final $\mathrm{pH}$ \\
SapCa-2 & 0.0 & 0.0 & 0.0 & 0.0 & 10.0 & 4.0 & 0.0 & 9.5 & 10.0 \\
SapCa-2 Ref & 0.0 & 0.0 & 0.0 & 0.0 & 7.0 & 2.0 & 0.0 & 9.5 & 9.5 \\
SWy-2 & 6.5 & 0.1 & 0.0 & 0.3 & 115 & 3.5 & 3.0 & 10.0 & 10.5 \\
SWy-2 Ref & 0.0 & 0.0 & 0.0 & 0.0 & 11.0 & 0.0 & 0.0 & 10.0 & 10.0 \\
Sbld & 2.0 & 0.4 & 0.0 & 0.3 & 17.0 & 28.0 & 14.0 & 7.5 & 7.5 \\
Sbld Ref & 0.0 & 0.0 & 0.0 & 0.0 & 1.0 & 2.0 & 1.0 & 7.5 & 7.5 \\
Garfield & 0.0 & 0.0 & 0.0 & 0.0 & 17.5 & 22.5 & 1.0 & 8.5 & 9.5 \\
Garfield Ref & 0.0 & 0.0 & 0.0 & 0.0 & 10.0 & 1.0 & 2.0 & 8.5 & 9.0 \\
\hline
\end{tabular}

Note: Concentrations are given in $\mathrm{mg}^{\mathrm{L}} \mathrm{L}^{-1}$. Initial and final $\mathrm{pH}$ values were measured before and after reaction, respectively. Regular sample names correspond to the reaction of a given smectite sample with metal iron for 45 days at $80^{\circ} \mathrm{C}$. Ref samples correspond to the reaction of a given smectite sample for 45 days at $80^{\circ} \mathrm{C}$ without metal iron.

Table3: Relative proportion of smectite destabilized (weight $\%$ ) as a function of the initial solution $\mathrm{pH}$.

\begin{tabular}{cccc}
\hline $\mathrm{pH}$ & SWy-2 & SapCa-2 & Garfield \\
6 & $0 \%$ & $0 \%$ & $0 \%$ \\
8 & $50 \%$ & - & $95 \%$ \\
10 & $50 \%$ & $0 \%$ & - \\
12 & $50 \%$ & - & - \\
\hline
\end{tabular}

Note: Relative proportion of destabilized

smectite is estimated using the XRD method.

Table 4: Relative proportion of smectite destabilized (weight $\%$ ) as a function of the cation interlayer composition.

\begin{tabular}{cccc}
\hline & SAz-1 & SWy-2 & Garfield \\
$\mathrm{K}$ & - & $0 \%$ & $50 \%$ \\
$\mathrm{Ca}$ & $20 \%^{*}$ & $20 \%$ & $95 \%^{*}$ \\
$\mathrm{Na}$ & $40 \%$ & $50 \%^{*}$ & -
\end{tabular}

Note: Relative proportion of destabilized smectite is estimated using the XRD method. * indicate raw samples, with the corresponding predominant interlayer cation. 
Figure 1 :

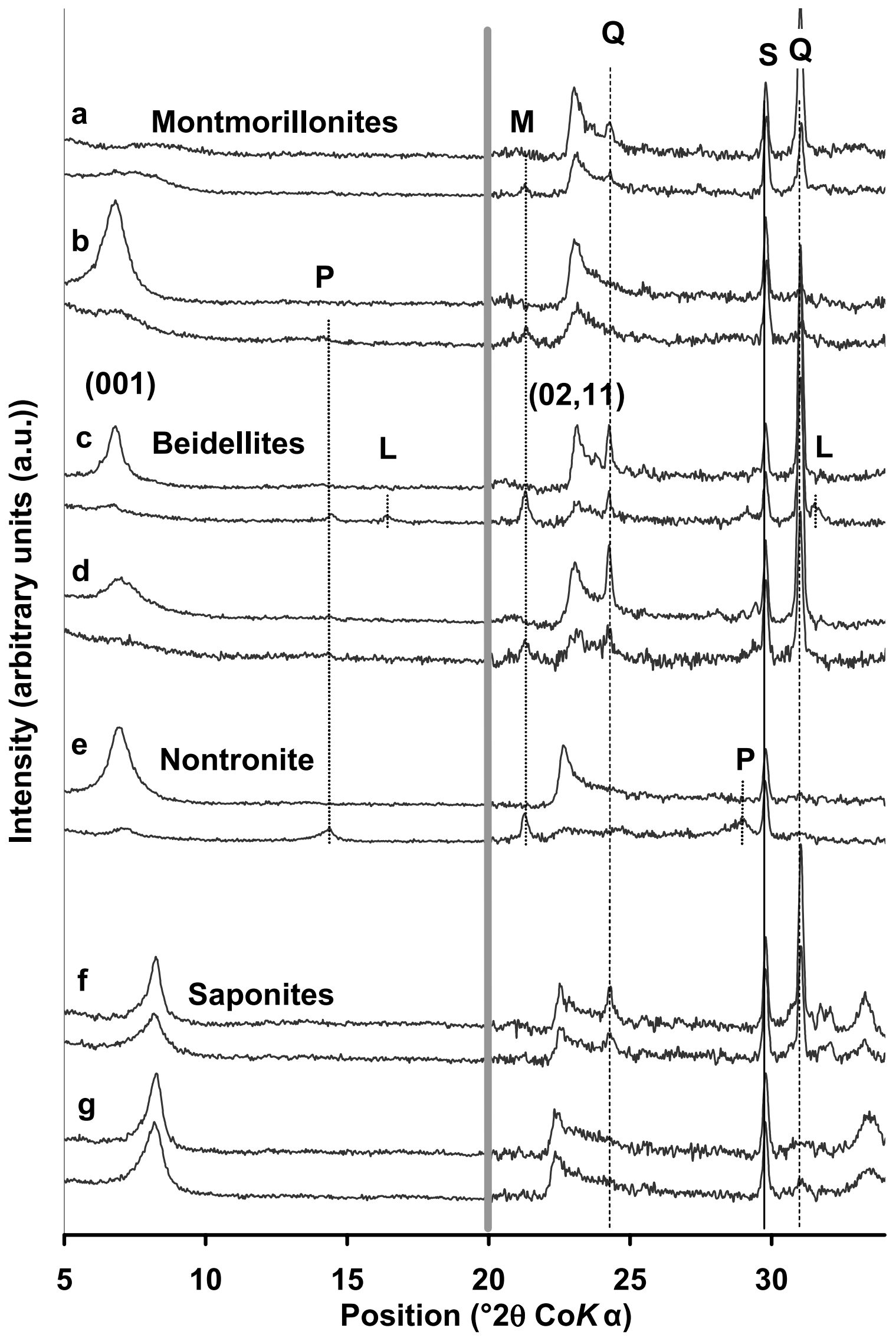


Figure 2:
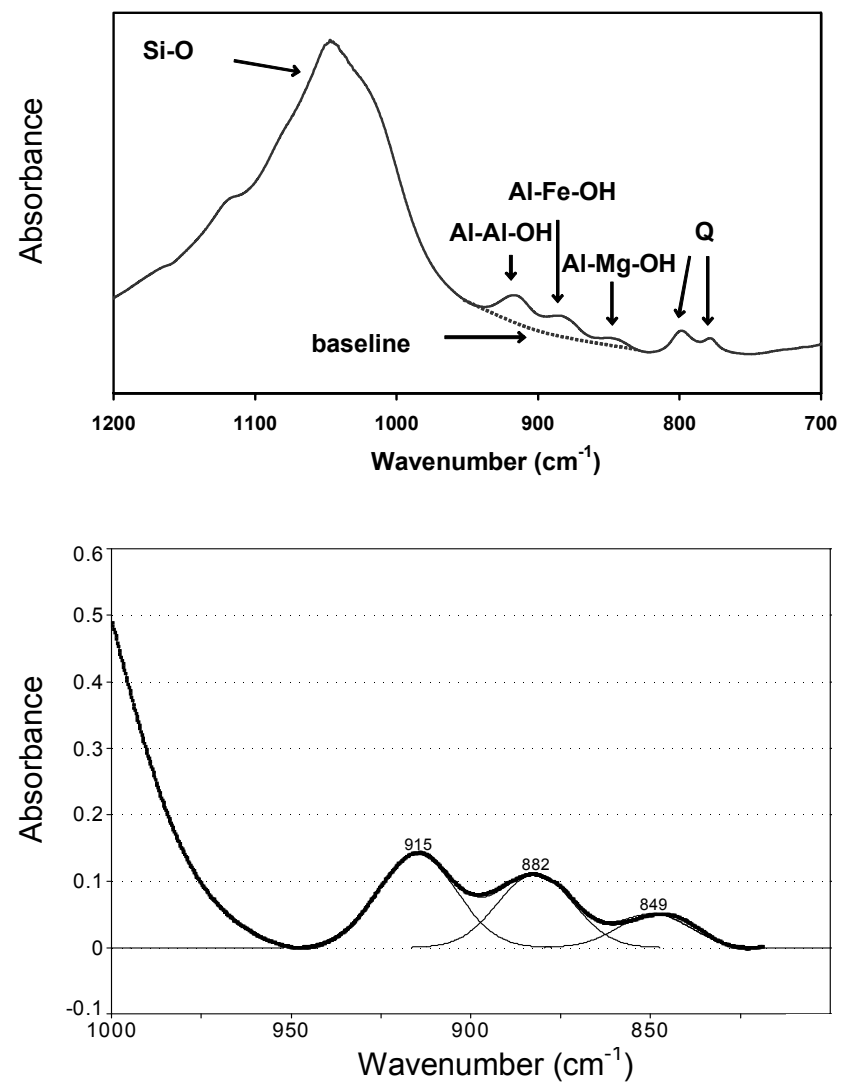

b 
Figure 3 :

a

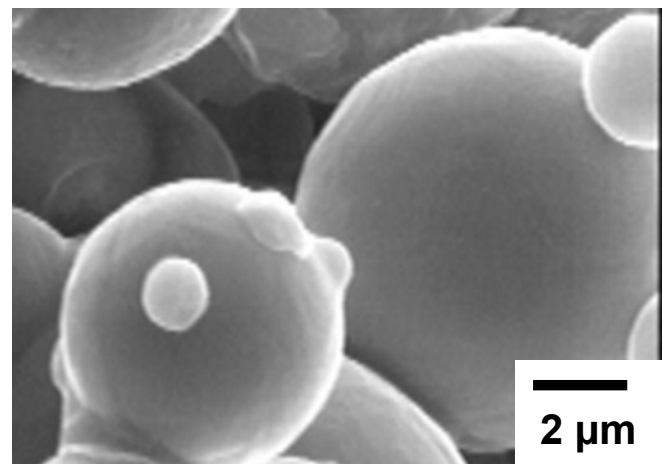

c

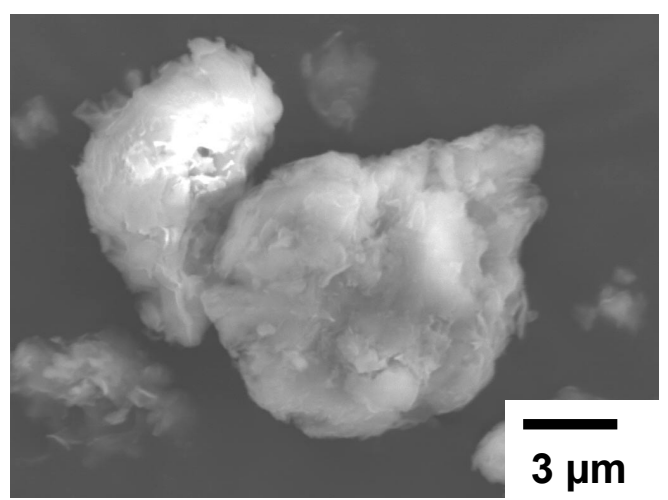

e

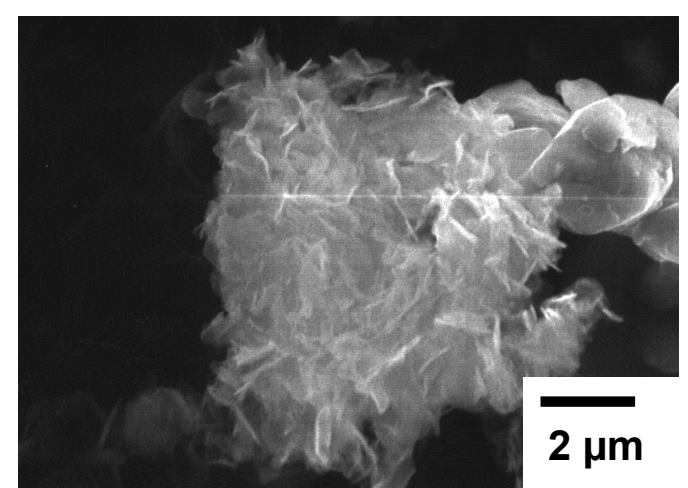

g

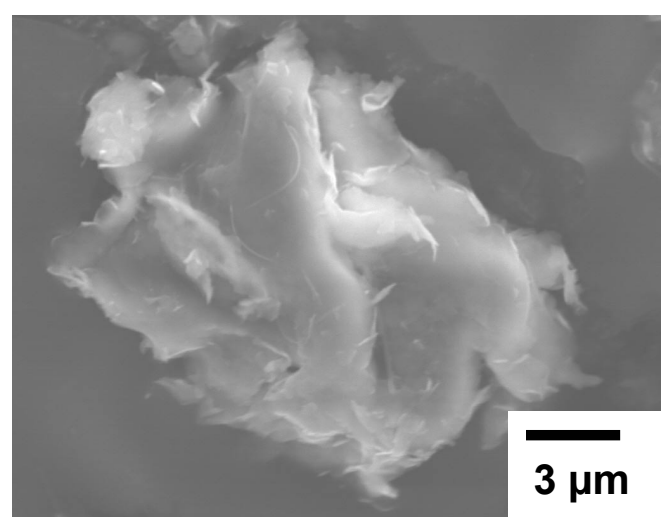

b

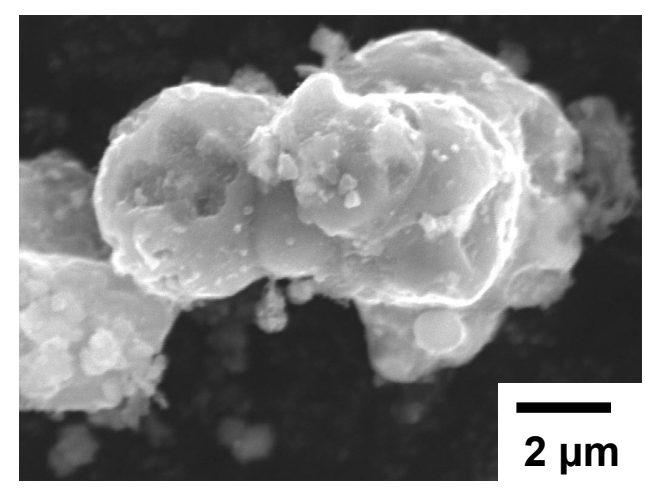

d

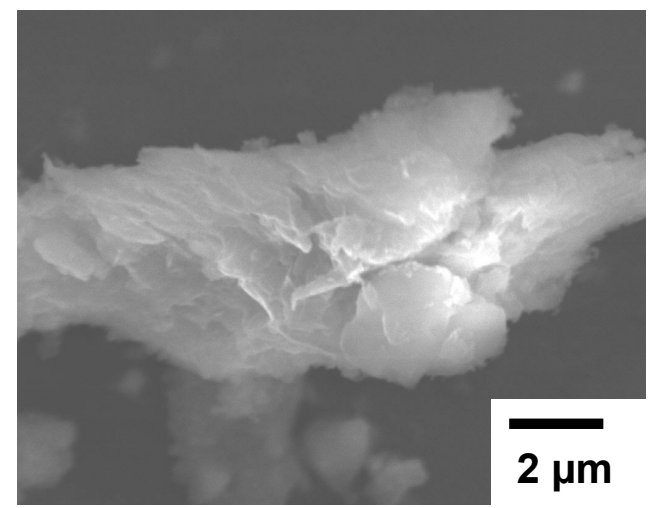

f

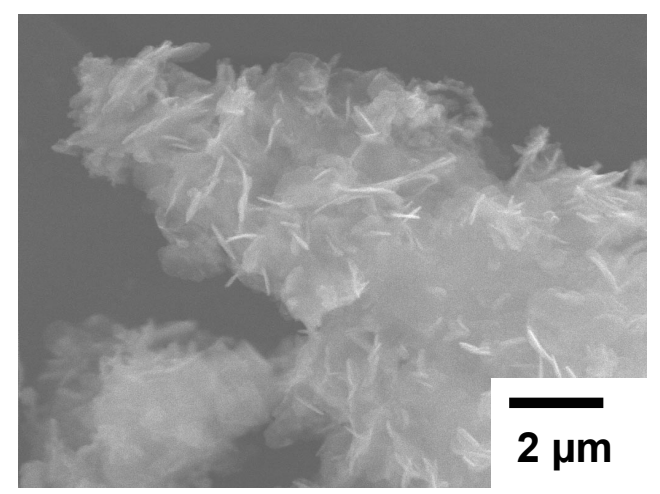

h

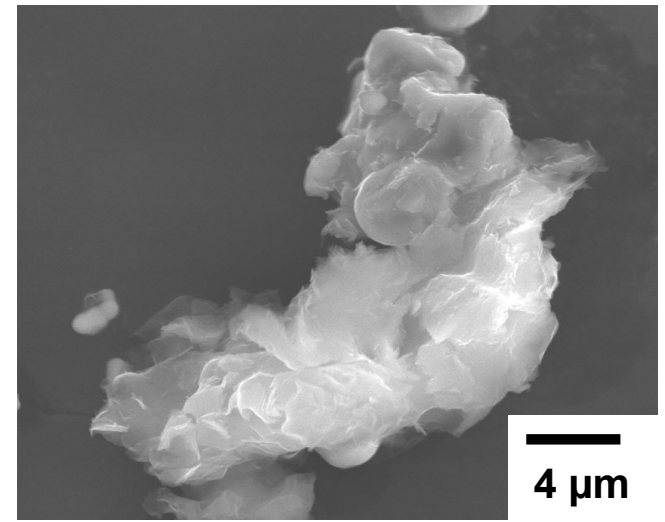


Figure 4 :

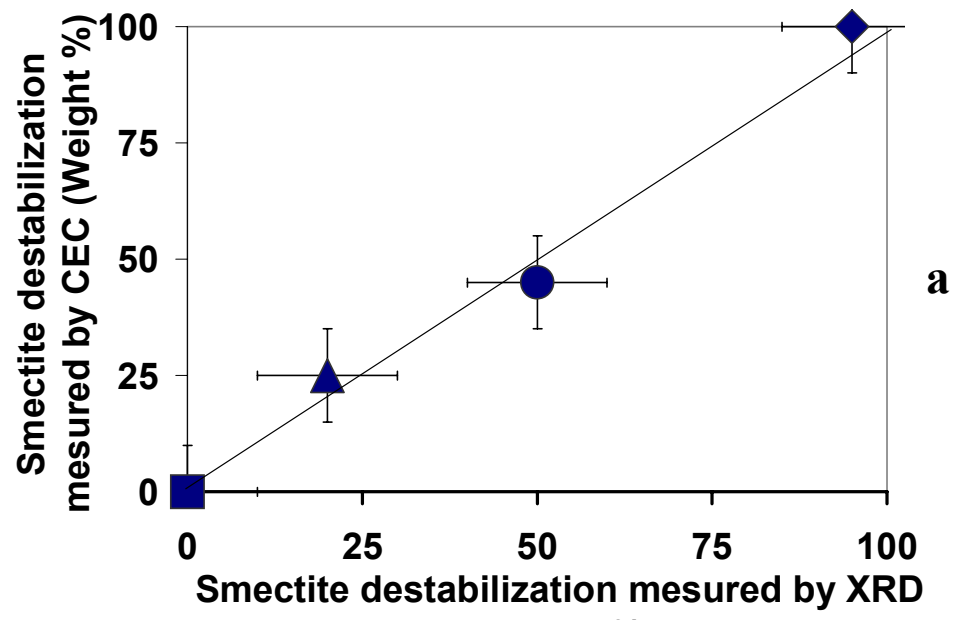

(Weight \%)

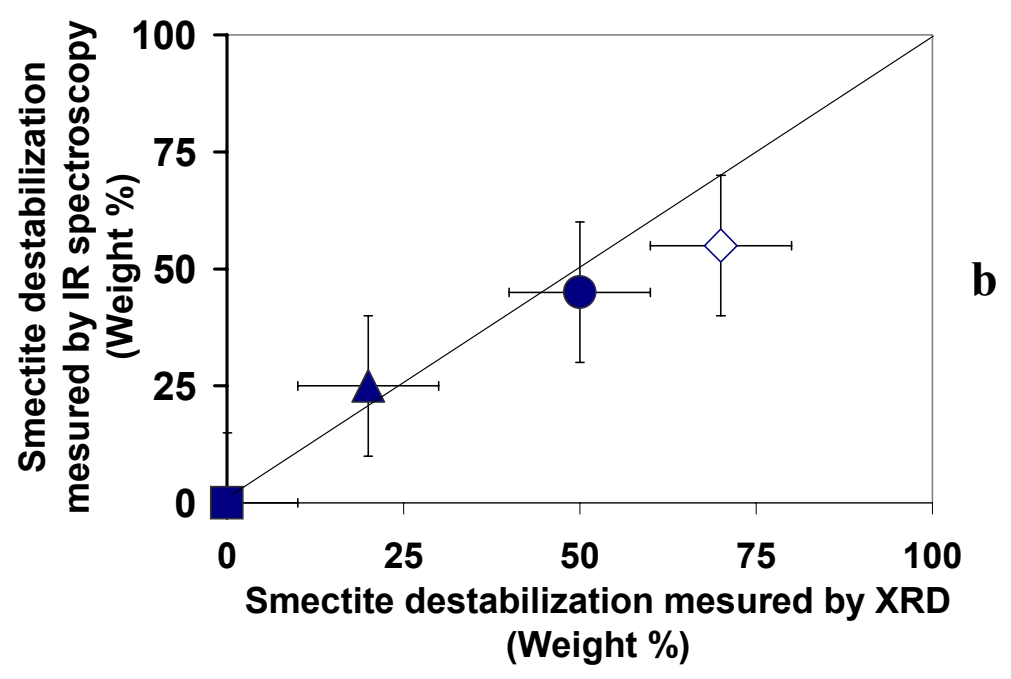


Figure 5 :

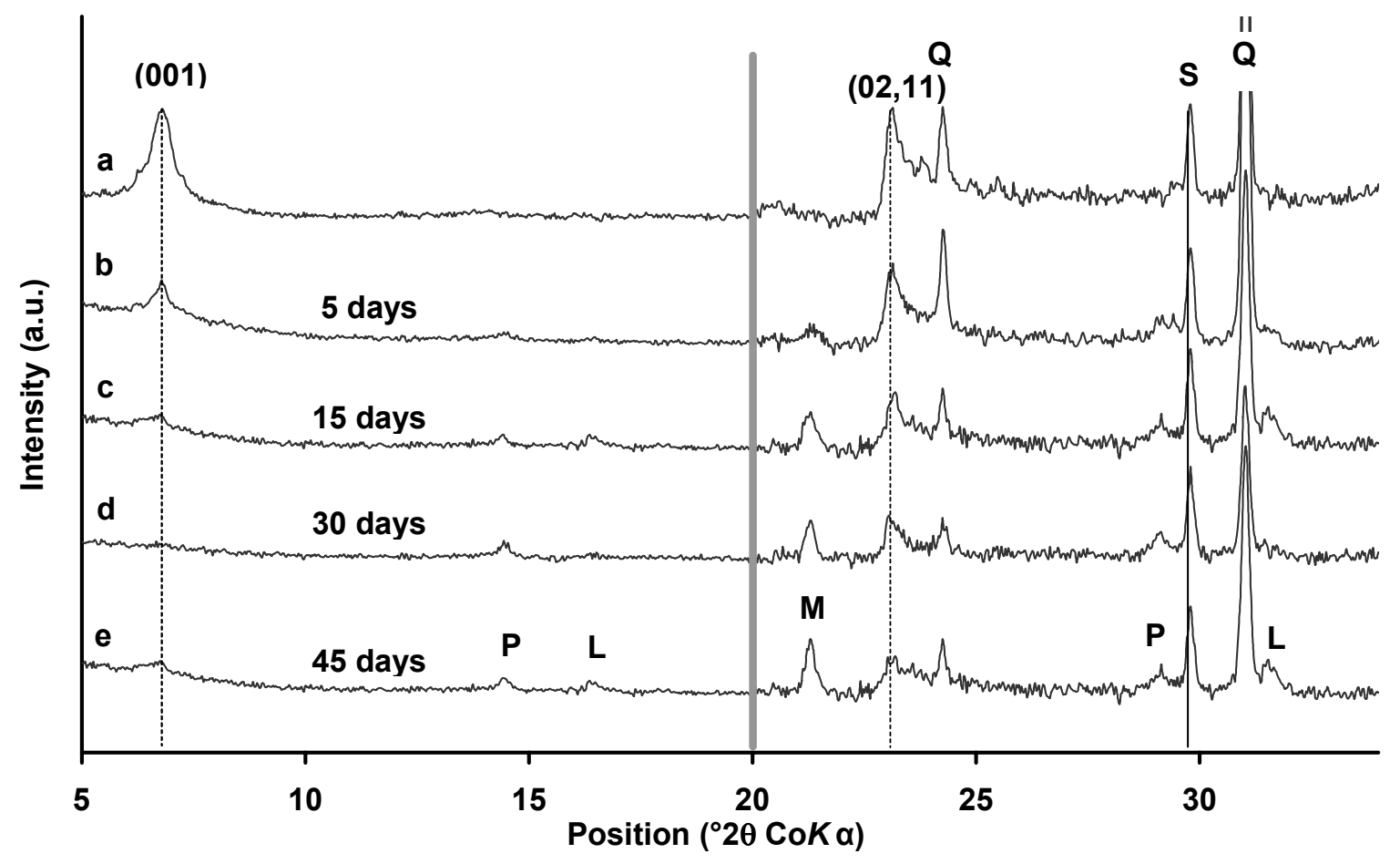

Figure 6 :

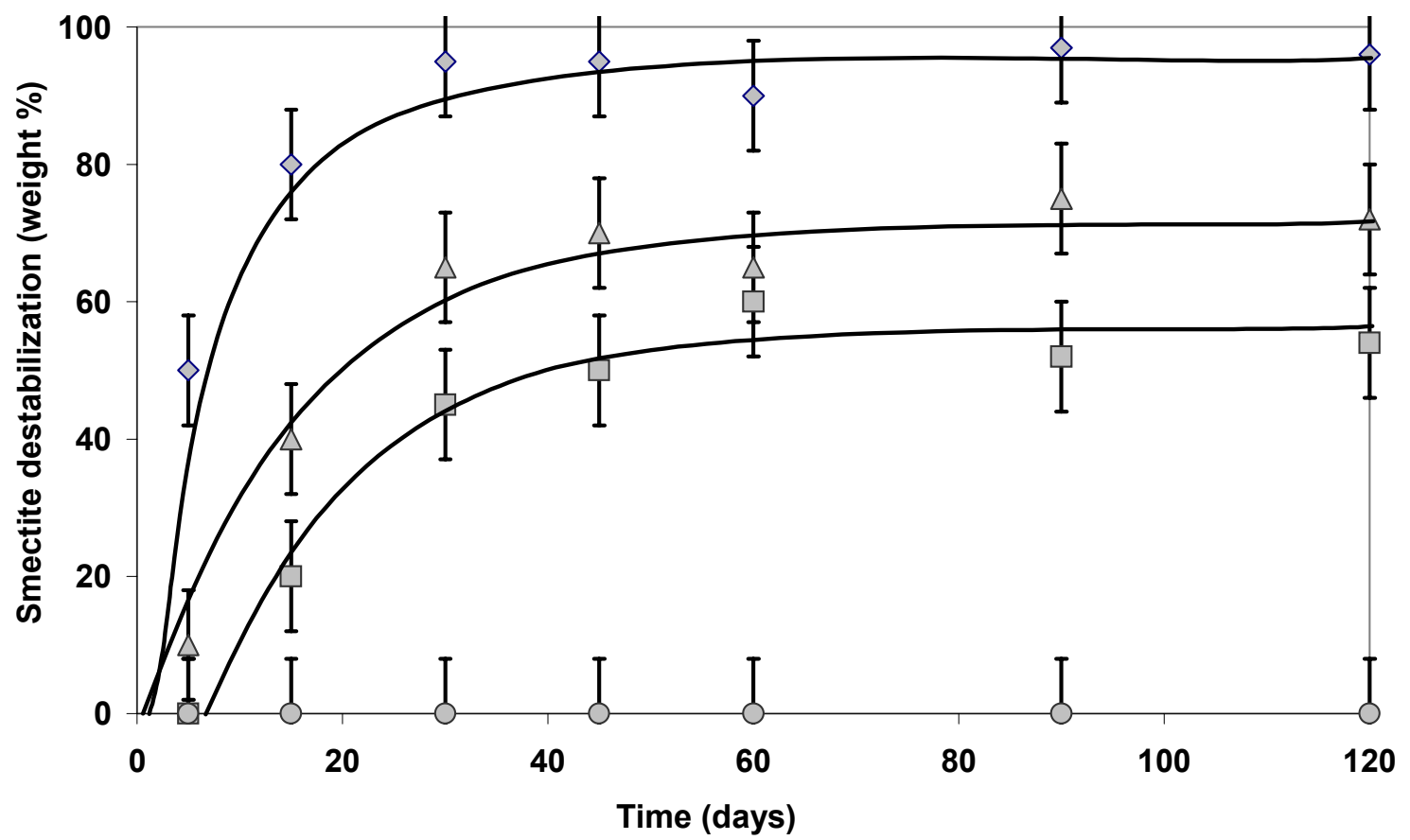


Figure 7 :

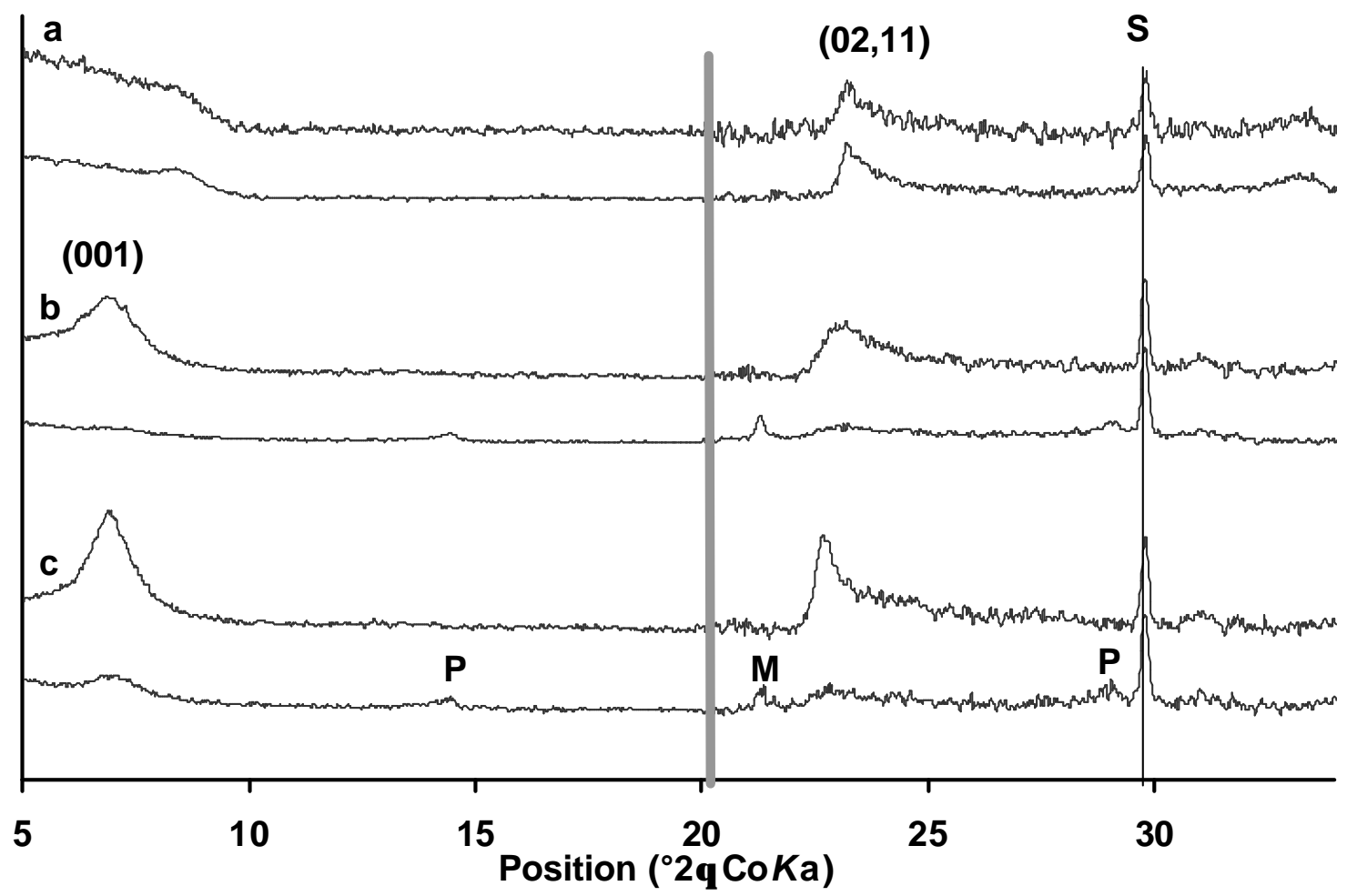

Figure 8 :

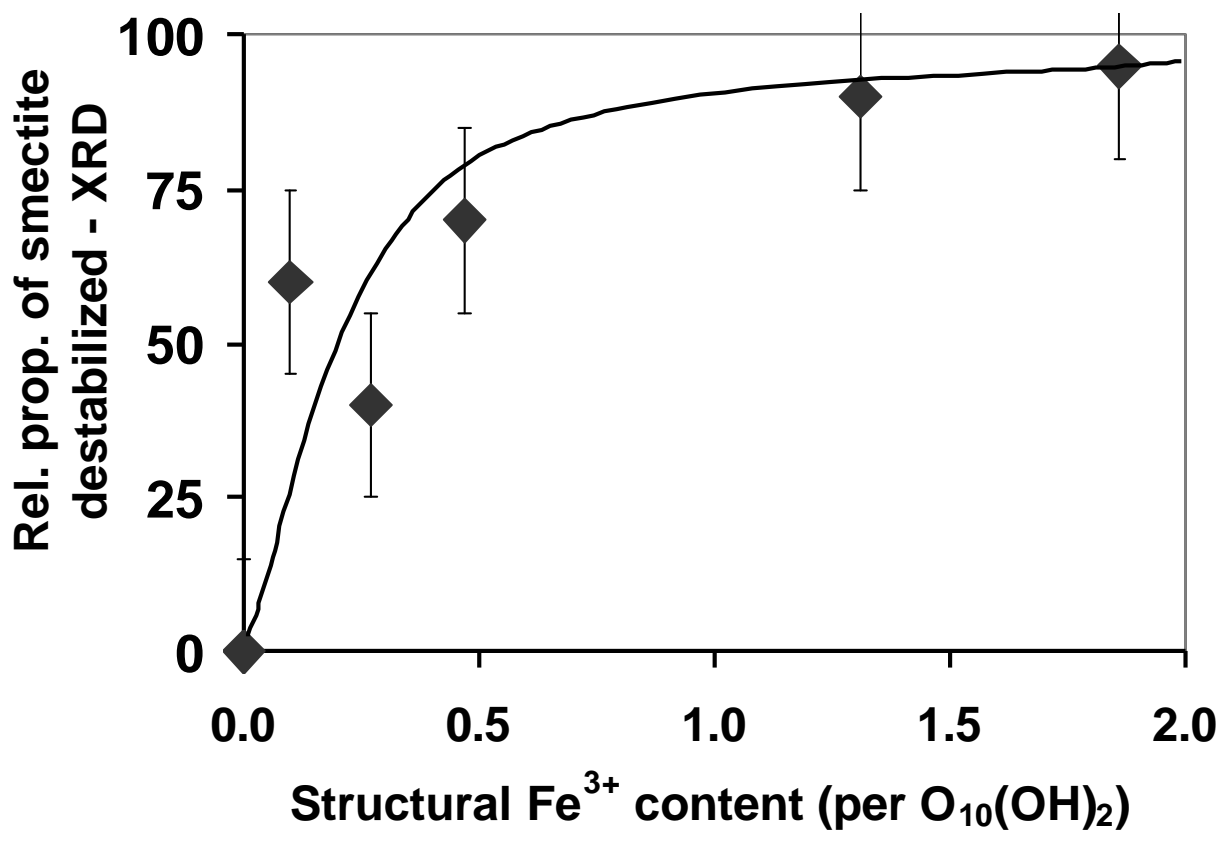


Figure 9 :

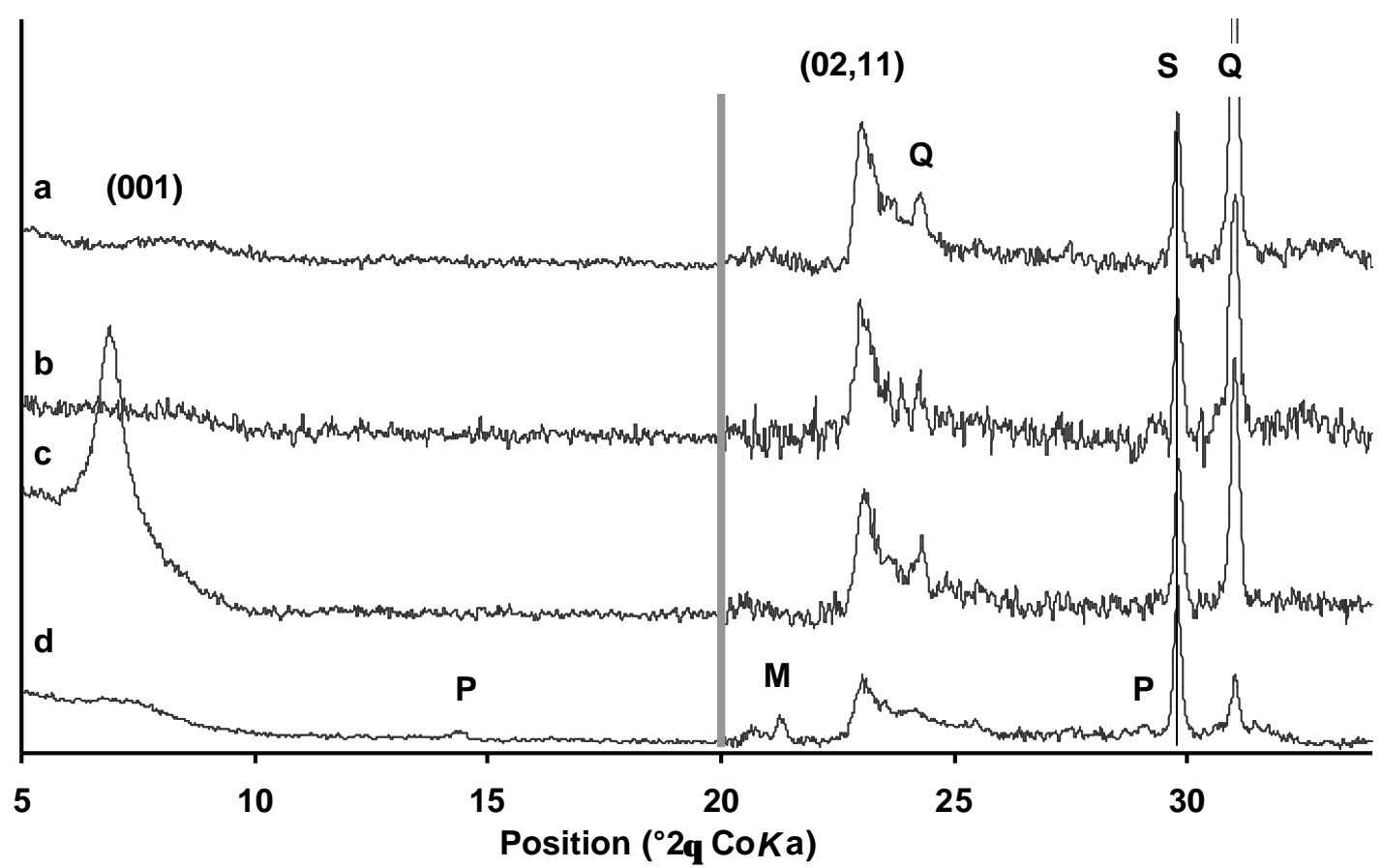

Figure 10 :

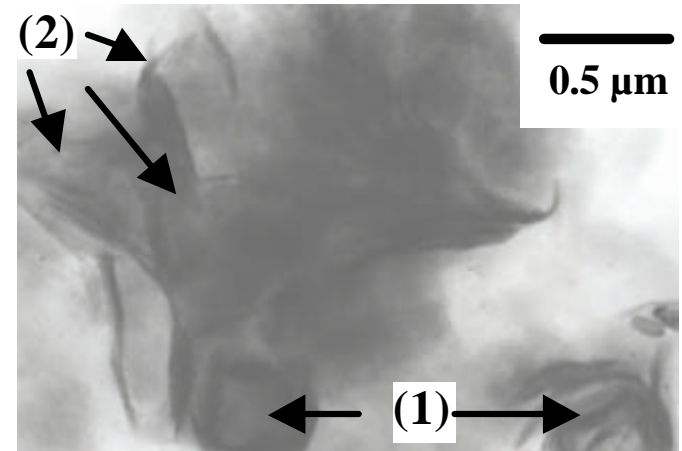


Figure 11
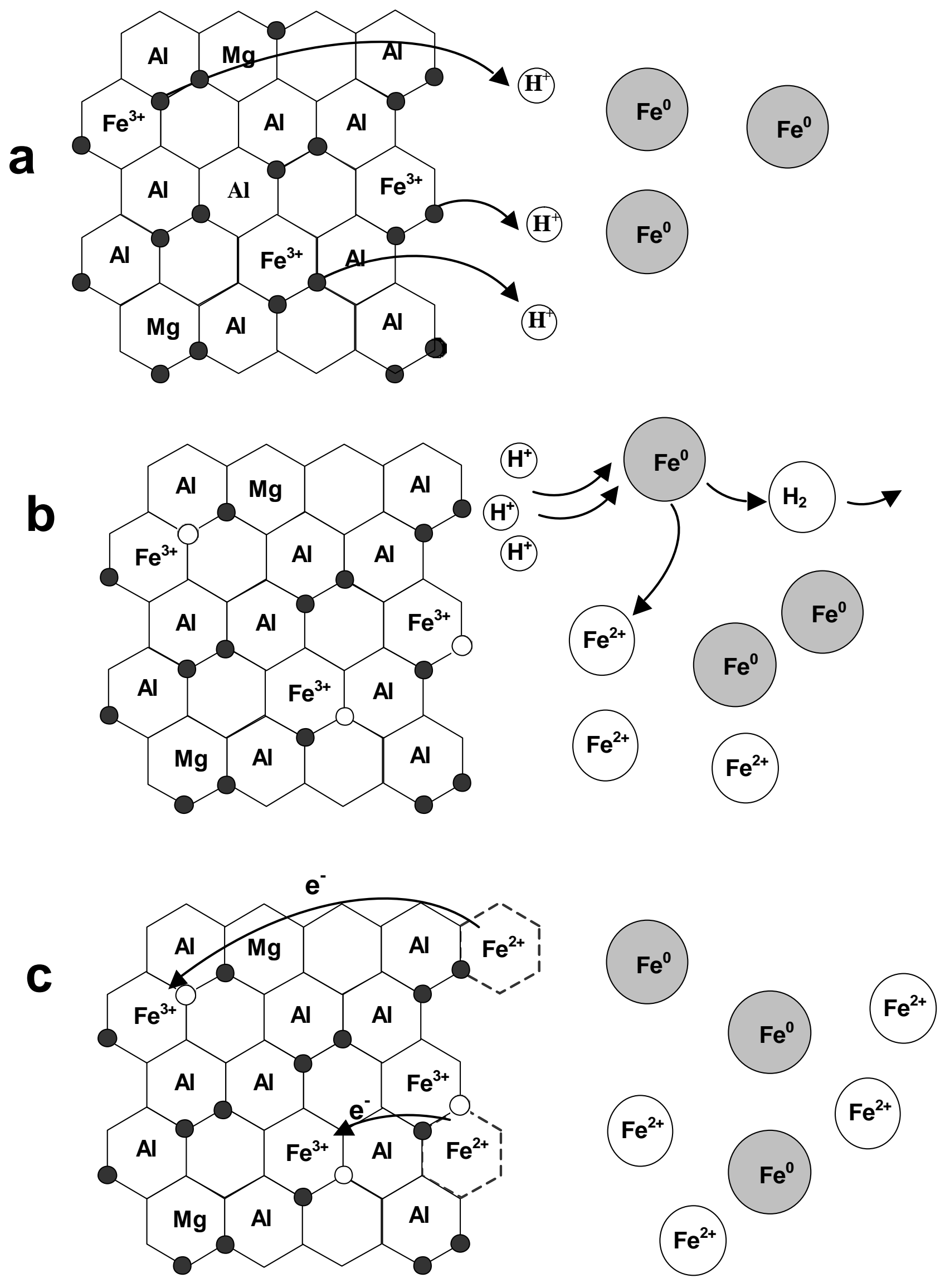

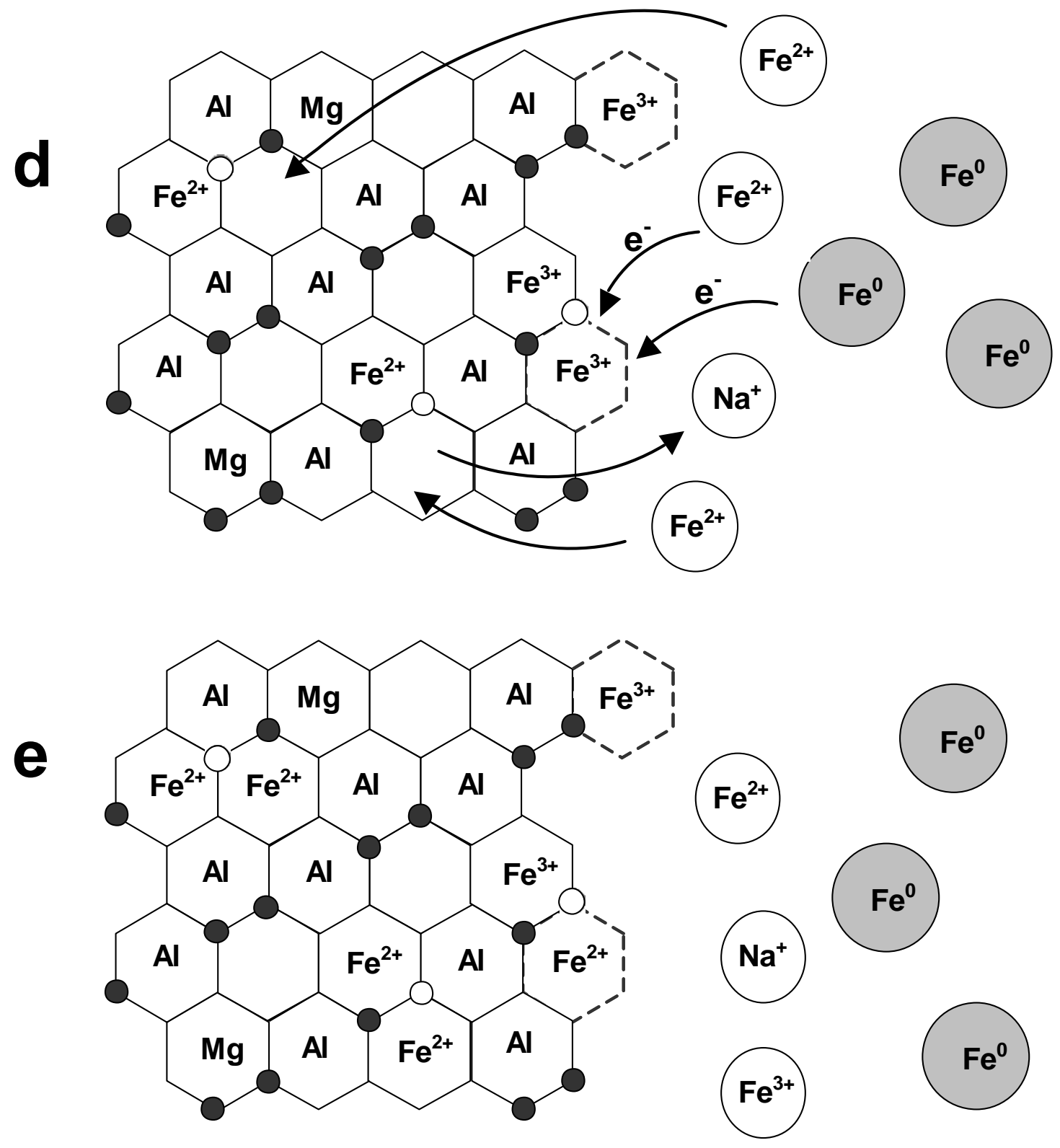